OPEN ACCESS

Edited by:

Vincenzo Scarlato,

University of Bologna, Italy

Reviewed by:

Xin Deng,

City University of Hong Kong,

Hong Kong

Attilio Fabbretti,

University of Camerino, Italy

${ }^{*}$ Correspondence:

Monique L. van Hoek mvanhoek@gmu.edu

Specialty section:

This article was submitted to Molecular Bacterial Pathogenesis,

a section of the journal

Frontiers in Cellular and Infection

Microbiology

Received: 01 December 2019 Accepted: 18 February 2020

Published: 13 March 2020

Citation:

Dean SN, Milton ME, Cavanagh J and van Hoek ML (2020) Francisella novicida Two-Component System Response Regulator BfpR Modulates ig/C Gene Expression, Antimicrobia

Peptide Resistance, and Biofilm Production.

Front. Cell. Infect. Microbiol. 10:82 doi: 10.3389/fcimb.2020.00082

\section{Francisella novicida Two-Component System Response Regulator BfpR Modulates igIC Gene Expression, Antimicrobial Peptide Resistance, and Biofilm Production}

\author{
Scott N. Dean ${ }^{1}$, Morgan E. Milton ${ }^{2}$, John Cavanagh ${ }^{2}$ and Monique L. van Hoek ${ }^{1 *}$ \\ ${ }^{1}$ National Center for Biodefense and Infectious Diseases, and School of Systems Biology, George Mason University, \\ Manassas, VA, United States, ${ }^{2}$ Department of Biochemistry and Molecular Biology, The Brody School of Medicine, East \\ Carolina University, Greenville, NC, United States
}

Response regulators are a critical part of the two-component system of gene expression regulation in bacteria, transferring a signal from a sensor kinase into DNA binding activity resulting in alteration of gene expression. In this study, we investigated a previously uncharacterized response regulator in Francisella novicida, FTN_1452 that we have named BfpR (Biofilm-regulating Francisella protein Regulator, FTN_1452). In contrast to another Francisella response regulator, QseB/PmrA, BfpR appears to be a negative regulator of biofilm production, and also a positive regulator of antimicrobial peptide resistance in this bacterium. The protein was crystallized and X-ray crystallography studies produced a $1.8 \AA$ structure of the BfpR N-terminal receiver domain revealing interesting insight into its potential interaction with the sensor kinase. Structural analysis of BfpR places it in the OmpR/PhoP family of bacterial response regulators along with WalR and ResD. Proteomic and transcriptomic analyses suggest that BfpR overexpression affects expression of the critical Francisella virulence factor iglC, as well as other proteins in the bacterium. We demonstrate that mutation of $b f p R$ is associated with an antimicrobial peptide resistance phenotype, a phenotype also associated with other response regulators, for the human cathelicidin peptide LL-37 and a sheep antimicrobial peptide SMAP-29. F. novicida with mutated $b f p R$ replicated better than WT in intracellular infection assays in human-derived macrophages suggesting that the down-regulation of iglC expression in $b f p R$ mutant may enable this intracellular replication to occur. Response regulators have been shown to play important roles in the regulation of bacterial biofilm production. We demonstrate that $F$. novicida biofilm formation was highly increased in the bfpR mutant, corresponding to altered glycogen synthesis. Waxworm infection experiments suggest a role of BfpR as a negative modulator of iglC expression with de-repression by $\mathrm{Mg}^{2+}$. In this study, we find that the response regulator $\mathrm{BfpR}$ may be a negative regulator of biofilm formation, and a positive regulator of antimicrobial peptide resistance in F. novicida.

Keywords: Francisella, response regulator, two component systems (TCSs), biofilm, antimicrobial peptide resistance 


\section{INTRODUCTION}

Francisella are Gram-negative, fastidious bacteria found primarily in the Northern Hemisphere. The genus is composed of several species, the most notable being the highly virulent Francisella tularensis, the causative agent of tularemia. Cases of tularemia in the United States are rare and recently increasing, and interest in Francisella-related research is high (Dennis et al., 2001; Oyston et al., 2004). This is due to recent outbreaks of tularemia around the world and the fact that $F$. tularensis is classified as a Category A Biological threat Agent. The lessvirulent environmental strain, $F$. novicida, is used as a model for Francisella studies due to its high genetic similarity (>97\%) to $F$. tularensis, genetic tractability, availability of transposon mutant library, and its biosafety level 2 status due to lack of infectivity for humans (Gallagher et al., 2007; Larsson et al., 2009; Enstrom et al., 2012; Kingry and Petersen, 2014).

F. novicida has been shown to form biofilms in vitro (Dean et al., 2009; Durham-Colleran et al., 2010; Margolis et al., 2010; Verhoeven et al., 2010; van Hoek, 2013). Biofilms play an important role in bacterial environmental survival and are often involved in pathogenicity and antimicrobial resistance. In Pseudomonas, Salmonella, and many other Gram-negative bacteria, biofilm formation is under the control of twocomponent systems. Two-component systems are ubiquitous bacterial communication models and are typically formed from a membrane bound sensor histidine kinase and a DNAbinding response regulator (Stock et al., 2000; van Hoek et al., 2019). An extracellular signal is detected by the sensor kinase, resulting in autophosphorylation of the sensor kinase. The phosphate group is then transferred to the response regulator. Upon phosphorylation, the response regulator changes from an "inactive" to "active" state. The activated response regulator then dictates cellular responses through transcriptional regulation. Response regulators are transcription factors composed of two domains, a receiver (REC) domain which is connected to a DNA-binding domain through a flexible linker. On a molecular level, the response regulator propagates the signal by accepting the phosphate onto a conserved aspartate located within the REC domain. Activation of the response regulator often causes the REC domain to form a dimer, bringing the DNA-binding domains into proximity (Gao and Stock, 2009). Dimer formation positions the two DNA-binding domains to better bind the two half sites of the response regulator's cognate promoter. Understanding the structure and function of response regulators is important for comprehending bacterial gene expression, and could play a role in the development of new antimicrobial therapies.

Only three response regulator (RR) genes have been identified in the Francisella genus. The two-component system gene organization varies across the different species (Figure 1; Larsson et al., 2005; van Hoek et al., 2019). F. novicida has three sensor kinase (SK) genes and three response regulator genes. Two sets of genes form complete two-component system pairs (Figure 1), while the last two genes are "orphaned" (van Hoek et al., 2019). F. tularensis Schu S4, the highly infectious humanvirulent Type A strain, encodes two sensor kinase genes, two

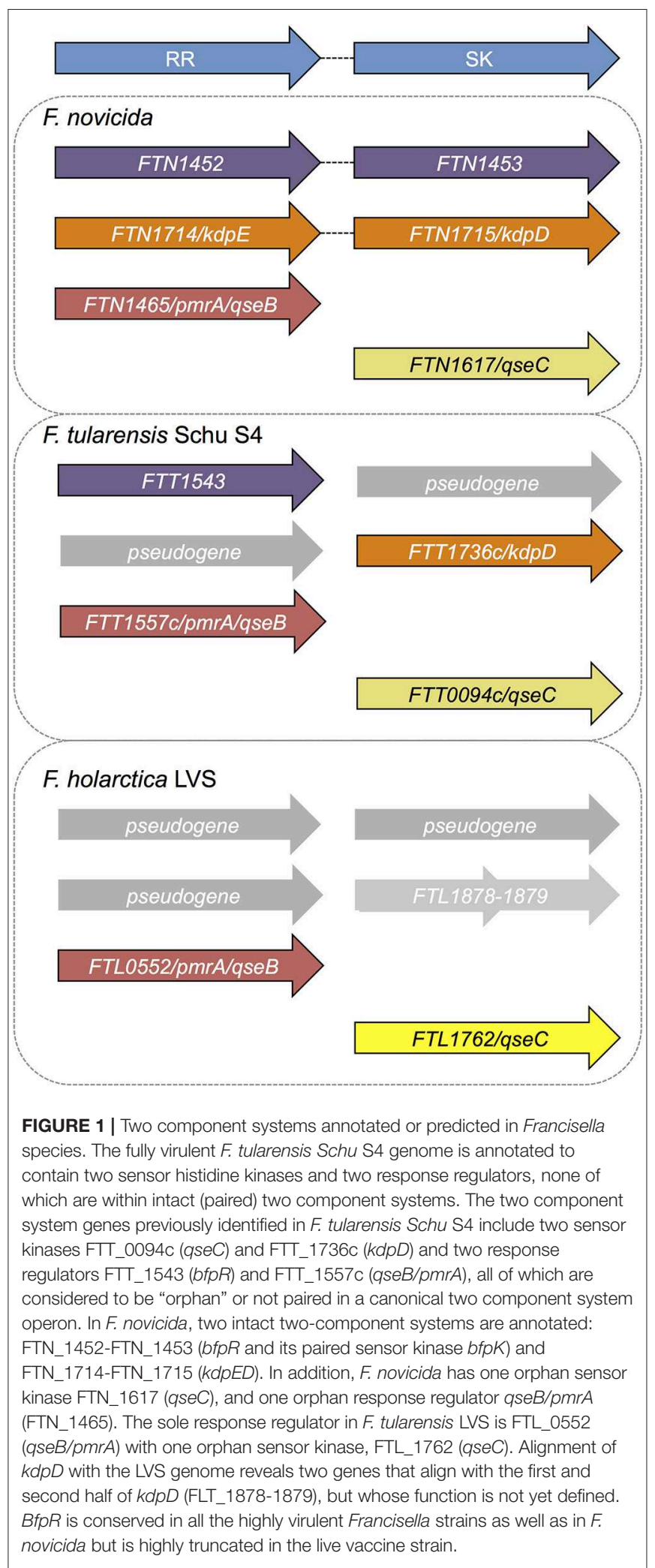

response regulator genes, and two pseudogenes. None of the two-component system genes are intact in the virulent strain $F$. tularensis (Figure 1). Pseudogene sequences contain early stop 
codons or shifts in the sequence, resulting in a truncated or non-functional gene product. F. holarctica Live Vaccine Strain (LVS) has one intact sensor kinase gene ( $q s e C$ ), only one response regulator gene, and pseudogenes present in place of the other three genes. Like F. tularensis, none of the LVS genes are within intact two-component systems. Finally, in F. philomiragia, an environmental strain, and F. noatunensis, a fish pathogenic strain, three sensor kinase genes and three response regulator genes were identified, similar to F. novicida (van Hoek et al., 2019). We previously investigated the role of the response regulator QseB/PmrA (FTN_1465) in biofilm formation in F. novicida (Durham-Colleran et al., 2010; van Hoek, 2013), and demonstrated that biofilm formation is dependent on both the orphan response regulator $(\mathrm{Q} s \mathrm{~B} / \mathrm{PrmA})$ and the orphan sensor kinase (QseC, FTN_1617). QseB/PmrA in F. novicida is critical for infection and has been identified as a potential virulence factor (Mohapatra et al., 2007; Bell et al., 2010). Overall, the role of the two-component system genes in Francisella physiology have not yet been fully elucidated (van Hoek et al., 2019). In this work, we examine the previously uncharacterized $F$. novicida response regulator FTN_1452.

Here, we report our efforts to characterize the F. novicida response regulator FTN_1452, which we have named BfpR (Biofilm-regulating Francisella protein Regulator). We explore the homology of BfpR across Francisella species, present the crystal structure of the REC domain, and investigate the impact of BfpR on gene expression and phenotype. Our findings led us to identify a role of $\mathrm{BfpR}$ within $F$. novicida including resistance to AMPs and biofilm formation.

\section{RESULTS AND DISCUSSION}

\section{Initial Identification of BfpR in Francisella}

We began our investigation exploring the conservation of FTN_1452 gene sequences between Francisella species and strains. We noted that F. novicida FTN_1452 is 100\% identical to F. tularensis SchuS4 FTT_1543 and $>90 \%$ identical to the F. philomiragia and F. noatunensis equivalents (Table 1, Figure S1C). In F. holarctica LVS and other holarctica strains, there is a truncated version of this response regulator (AJI58249, locus tag AW21_1440). The gene encodes only 123 of the 229 amino acids for the full-length protein. The first 56 and last 57 amino acids are missing, including the conserved aspartate which acts as the phosphoacceptor site (Figure S1E). Since the aspartate is required for response regulator activation, it is predicted that this pseudogene will be inactive.

Alignments of FTN_452 to other bacterial response regulators (Table 1, Figure S1A) suggest that FTN_1452 is a member of the OmpR/PhoP family (Figure S1D). While FTN_1452 shares sequence similarity around the phosphorylation activity site, overall homology is only significant within the genus Francisella (Figures S1A-C). Sequence analysis showed low levels of similarity by sequence to WalR of Staphylococcus aureus (38\%), PhoP of Pseudomonas aeruginosa (40\%), and MprA of Mycobacterium tuberculosis (37\%) (Table 1). Thus, FTN_1452 could not be named as a close homolog to any known response regulator in other bacteria and was given the name
TABLE 1 | Sequence comparison of BfpR with other well-known response regulators.

\begin{tabular}{llcc}
\hline Protein & Organism & E-value & Identity (\%) \\
\hline FT1543 & Francisella tularensis & -168 & 100 \\
MprA & Stenotrophomonas maltophilia & -59 & 41 \\
PhoP & Xanthomonas campestris & -49 & 39 \\
CopR & Pseudomonas aeruginosa & -51 & 38 \\
WalR & Staphylococcus aureus & -43 & 38 \\
MprA & Mycobacterium tuberculosis & -54 & 37 \\
PhoP & Listeria monocytogenes & -46 & 37 \\
YedW & Salmonella typhimurium & -46 & 37 \\
PhoP & Bacillus subtilis & -46 & 37 \\
PhoP & Staphylococcus epidermidis & -44 & 35 \\
CopR & Escherichia coli & -47 & 34 \\
IrlR & Burkholderia pseudomallei & -40 & 33 \\
\hline
\end{tabular}

Sequence homology comparison of BfpR protein of $F$. novicida and response regulators of other selected bacterial pathogens. Only the most highly homologous protein from each organism is shown. This sequence comparison suggests that BfpR is not highly homologous by sequence to any known response regulators of other bacterial pathogens.

BfpR. BfpR stands for Biofilm-regulating Francisella protein Response regulator, for its involvement in biofilm formation as a significant phenotype (see below). NCBI conserved domain analysis (Figure S1D) also confirmed that BfpR is composed of a YesN/AraC superfamily REC domain and a helixturn-helix DNA-binding domain. These conserved domains are highly characteristic of bacterial two-component system response regulators. Using BLAST analysis of Francisella genomic sequences, we further confirmed that $\mathrm{BfpR}$ in F. novicida is identical to FTT_1543 in F. tularensis Schu S4, and this gene does not have any close homologs outside of the genus Francisella (Figure S1). Thus, by this analysis, BfpR is likely to be a response regulator involved in bacterial signal transduction mechanisms and regulation of transcription in F. novicida.

In $F$. novicida, $b f p R$ is encoded in a presumed operon with a sensor kinase, FTN_1453, making a complete two-component system with the response regulator gene appearing first and the sensor kinase gene second in the proposed operon. Interestingly, the sensor kinase gene is absent in F. tularensis SchuS4, but is present in the environmental and piscine strains, such as $F$. philomiragia and F. noatunensis (van Hoek et al., 2019). The absence of a cognate sensor kinase in the human-virulent strain of F. tularensis (FTT_1542 is a pseudogene) suggests that $b f p R$ may have to act as an orphaned TCS gene in the virulent F. tularensis. Alternatively, perhaps the fact that F. tularensis has a duplicated Francisella pathogenicity island (FPI) compared to F. novicida reduces the need for this TCS in the virulent strain.

Two-component systems can regulate environmental survival as well as virulence of bacteria, among other pathways. No published virulence factor screening studies have identified the FTT_1542 or FTN_1452 gene as required for Francisella infection in various models (Moule et al., 2010). This is consistent with the results shown below in which the transposon insertion mutant of $b f p R$ shows little or a positive effect on intracellular replication, while overexpression of $b f p R$ leads to significant inhibition in intracellular replication. Additional experiments 

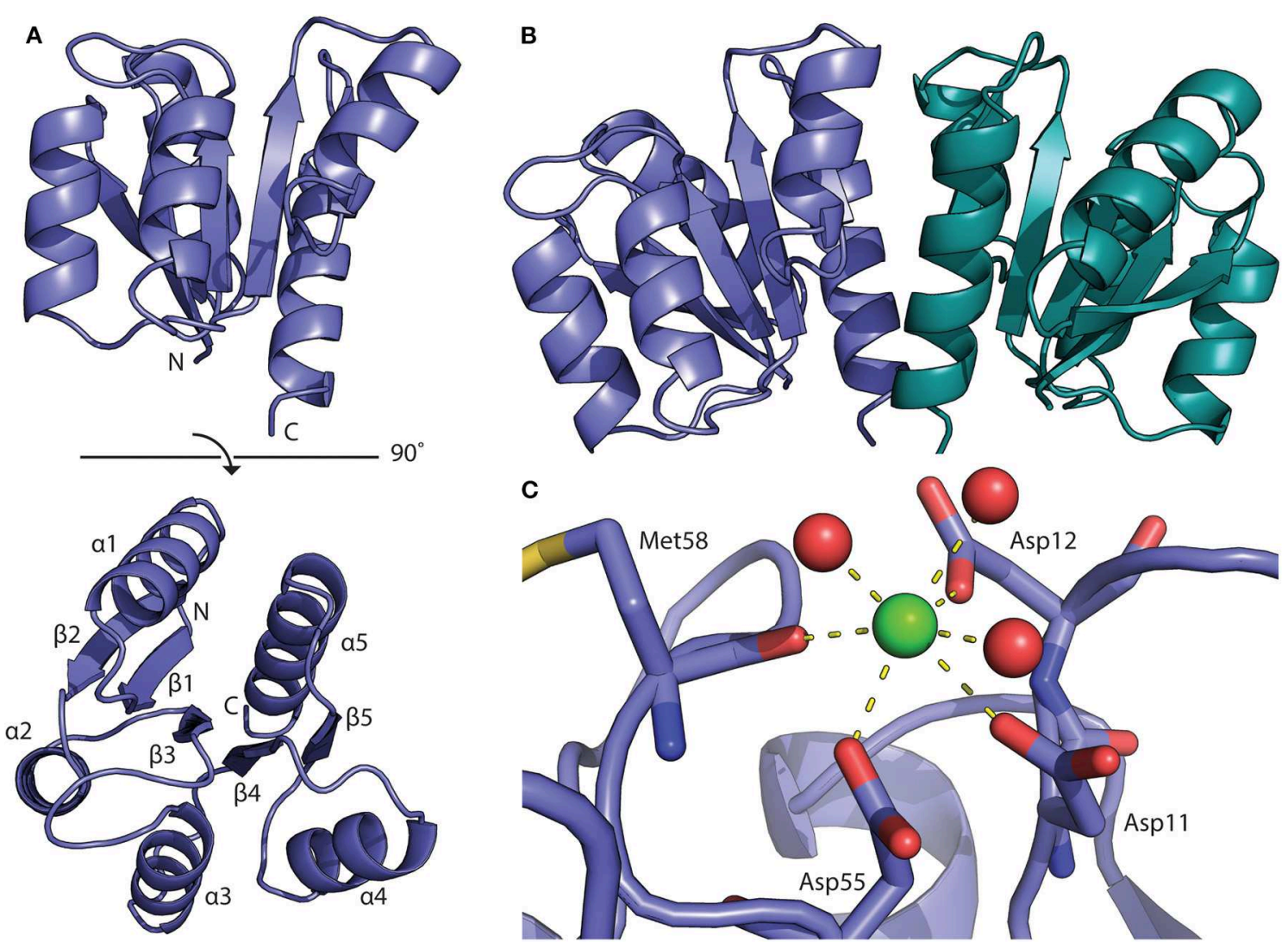

FIGURE 2 | Structure of the BfpR receiver domain. (A) Crystal structure of the N-terminal BfpR receiver domain solved to $1.8 \AA$. (B) Structure of BfpR receiver domain dimer with one monomer in blue and one in green. An adjacent symmetry mate forms the biologically relevant dimer. (C) Phosphorylation occurs at the conserved aspartate residue (Asp55). A calcium ion (green spheres) is located in the active site and is coordinated with active site residues and water molecules (red spheres) as seen in crystal structure of other phosphorylated response regulators.

detailing the effect of the $b f p R$ mutant and its ability to interact with potential signaling partners would be needed to fully understand this outcome. Since F. novicida is considered more of an environmental organism, while F. tularensis is a eukaryotic pathogen, the role of the $\mathrm{BfpR}$ response regulator may be more significant when measured with respect to phenotypes that may promote environmental survival, such as biofilm formation.

\section{Structure of BfpR N-Terminal Receiver Domain}

The structure of the BfpR N-terminal REC domain (BfpRN) was solved using X-ray crystallography (Figure 2A). Cubic crystals grew within $48 \mathrm{~h}$ in $0.2 \mathrm{M}$ calcium chloride, $0.1 \mathrm{M}$ HEPES $\mathrm{pH}$ 7.5 , and $28 \%$ polyethylene glycol 400 using hanging-drop vapor diffusion. The resulting crystals had an $I 4_{1} 32$ space group and unit cell dimensions of $\mathrm{a}=\mathrm{b}=\mathrm{c}=128.726 \AA$ and $\alpha=\beta=\gamma=$ $90^{\circ}$ (Table S2). The N-terminal domain of QseB from $F$. novicida [PDB ID 5UIC, (Milton et al., 2017)] was used as the model for the molecular replacement solution. The structure was refined to $1.80 \AA$ resolution with a crystallographic $R_{\text {work }}$ of 0.1824 and $R_{\text {free }}$ of 0.2019 . Refinement resulted in no Ramachandran outliers and $98.32 \%$ favored. The BfpRN construct used for crystallization was composed of residues Met1 to Ala129 with three additional
$\mathrm{N}$-terminal residues remaining after cleavage of the affinity tag. Only residues Asn4 through Lys124 could be traced into the electron density.

As expected from our sequence homology observations, the structure shares the canonical OmpR/PhoP receiver domain with an alternating $\alpha / \beta$-fold consisting of 5 -helices and 5 -strands (Figure 3; Bourret, 2010). Structural alignment of BfpR with an array of other OmpR/PhoP family receiver domains the high level of structural similarity between the receive domain of these response regulators. On average, the $\mathrm{C} \alpha$ backbone align with an average RMSD of about $0.9 \AA$ across $\sim 110$ atoms (Figure 3). The asymmetric unit of BfpR contains one monomer with an adjacent symmetry mate forming the biologically relevant dimer (Figure 2B) as described previously (Milton et al., 2017; Draughn et al., 2018). The dimer $\alpha 4-\beta 5-\alpha 5$ interface of BfpR contains major salt bridges between Lys92 and Glu112, Asp102 and Arg116, and Asp101 and Arg123. These residues have been shown to have homology in other OmpR/PhoP family response regulators (Draughn et al., 2018). The BfpR active site contains the canonical conserved aspartate residues, including the phosphorylation site at Asp55. A calcium ion is coordinated into the position of the active site magnesium (Figure 2C). It has been previously demonstrated that the crystal lattice appears to 


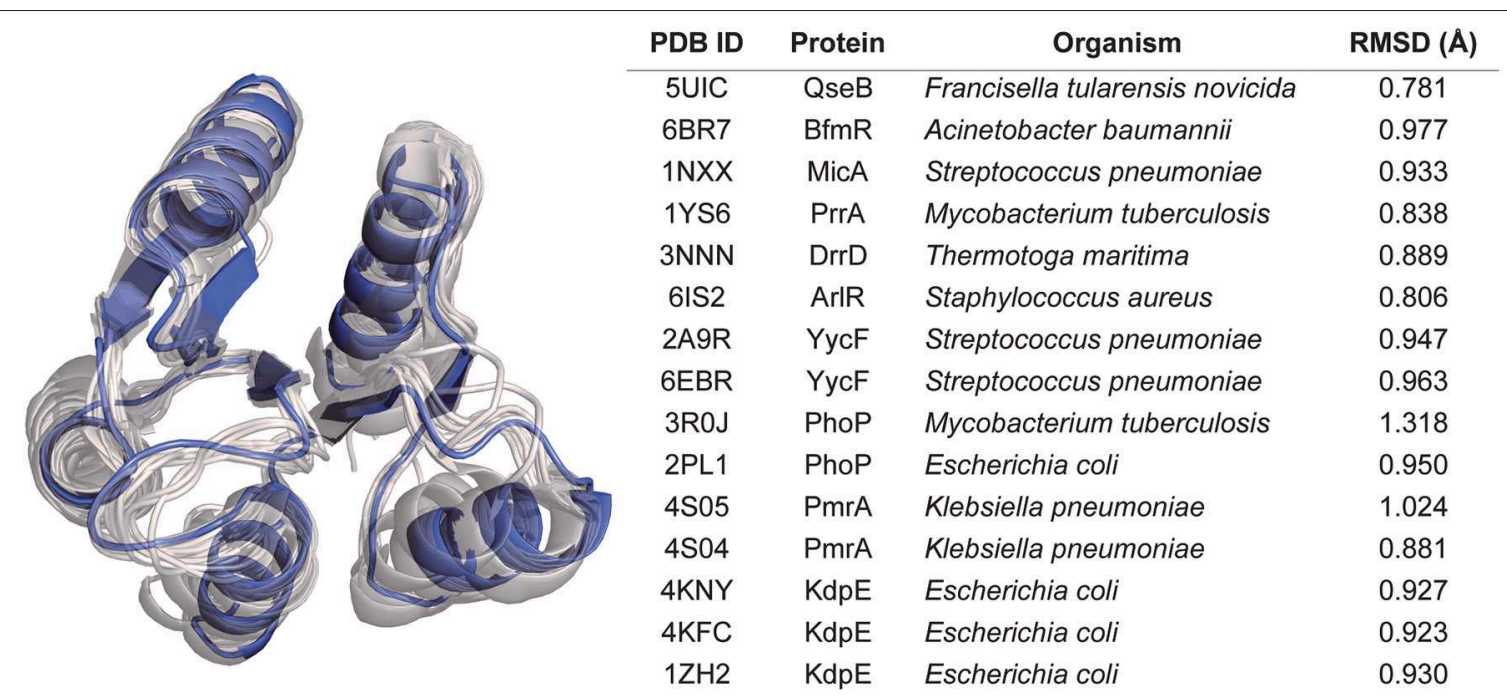

FIGURE 3 | Structural comparison of BfpR and other response regulators. Alignment of our BfpR structure to 15 other response regulators in the Protein Data Bank (PDB) demonstrates the high level of structural similarity between the BfpR and other OmpR/PhoP response regulator receiver domains. BfpR is shown in blue (left) with other response regulators in gray. The table (right) denotes the PDB ID for each structure used along with the C $\alpha$ RMSD. RMSD values were calculated from the alignment of each PDB entry to BfpR in PyMol.

trap the response regulator in an active state, even in the absence of phosphate or a phosphomimic (Draughn et al., 2018). This was demonstrated with the response regulator BfmR, the master biofilm regulator from Acinetobacter baumannii. Alignment of active site residues of BfpR to BfmR bound to a phosphomimic results in an RMS of $0.290 \AA$. This strongly suggests that BfpR contains a functional phosphorylation site.

\section{Transcriptomic Analysis of $b f p R$ Mutant and $b f p R$ Overexpressing Strain}

To investigate the effect of BfpR on gene transcription in F. novicida, we performed RNAseq analysis. We assessed the effect of the $b f p R$ transposon-insertion mutant (Gallagher et al., 2007) and by overexpressing $b f p R$ using the Francisella gro promoter. The overexpression of response regulators and other transcriptional regulators has been previously found to be a useful method for understanding the impact of a specific regulator on Escherichia coli and Saccharomyces cerevisiae (Nishino and Yamaguchi, 2001; Tanaka et al., 2012). We used this method for studying BfpR's effect on gene expression and other outputs throughout this study in F. novicida.

We compared wild type F. novicida (WT) gene expression to a $b f p R$ transposon-insertion mutant (Gallagher et al., 2007) and the BfpR overexpressing strain $\left(b f p R^{o x}\right)$ (Table S1). While RNA-Seq data is typically presented as the expression level in the $b f p R$ mutant compared to the WT, we also calculated the ratio change in the $b f p R^{o x}$ overexpression mutant vs. the $b f p R$ mutant (Figure S2A). The results confirmed the high level of $b f p R^{o x}$ compared to WT (Figure S2B). The results indicate broad effects of $b f p R$ and the $b f p R^{o x}$ on $F$. novicida, including a downregulation of fatty acid metabolism and the FPI genes in both the $b f p R^{o x}$ vs. $b f p R$ and WT vs. $b f p R$ comparisons (Figure 4).
Many proteins encoded by the Francisella Pathogenicity Island (FPI) have been shown to be virulence factors, especially intracellular growth locus C, iglC (Nano et al., 2004). As part of its intracellular replication, $F$. tularensis escapes from the phagosome into the cytoplasm in an iglC-dependent manner where it replicates further, making iglC a required virulence factor for Francisella (Lai et al., 2004; Lindgren et al., 2004). IglC is part of the newly discovered Type VI secretion system in Francisella. Using KEGG analysis of the RNAseq data, the entire FPI was a significantly down-regulated pathway (down an average of 5-fold), with intracellular growth locus A (iglA) down-regulated $\sim 18$-fold, iglC expression downregulated $\sim 15$ fold, and all members of the FPI significantly changed in the $b f p R^{o x}$ (Figure 4, Figure S2A). This suggests that the pathogenicity of the $b f p R^{o x}$ bacteria may be significantly reduced, as iglC expression (downregulated $\sim 15$ fold in the $b f p R^{o x}$ ) is required for intracellular replication and pathogenesis (Lai et al., 2004). As an example of the effect on metabolic genes, alcohol dehydrogenase, $a d h C$, was down 32 -fold, and members of the fad operon significantly changed in the both mutant and $b f p R^{o x}$ comparisons.

Gene expression of the acid phosphatase AcpA was not significantly changed by overexpression of $b f p R$ but changed $(\sim 2$-fold) in the WT vs. $b f p R$ comparison. Importantly, the $b f p R^{o x}$ strain displayed a $>100$-fold increase in $b f p R$ transcripts compared to WT and $b f p R$ mutant, confirming that this strain was indeed overexpressing $b f p R$ (Figures S2A,B). Of all the TCS genes, qseB (FTN_1465) was the least affected by $b f p R^{o x}$ (Figure S2B). Overall, these results suggest the broad range of genes controlled directly or indirectly by BfpR.

In comparing the proteomic (Figure S2C) and transcriptomic (Figure S2A) results, a glycogen synthesis gene $g \lg C$ was found to be downregulated (6.5-fold) in $b f p R^{o x} v s . b f p R$, consistent with its 


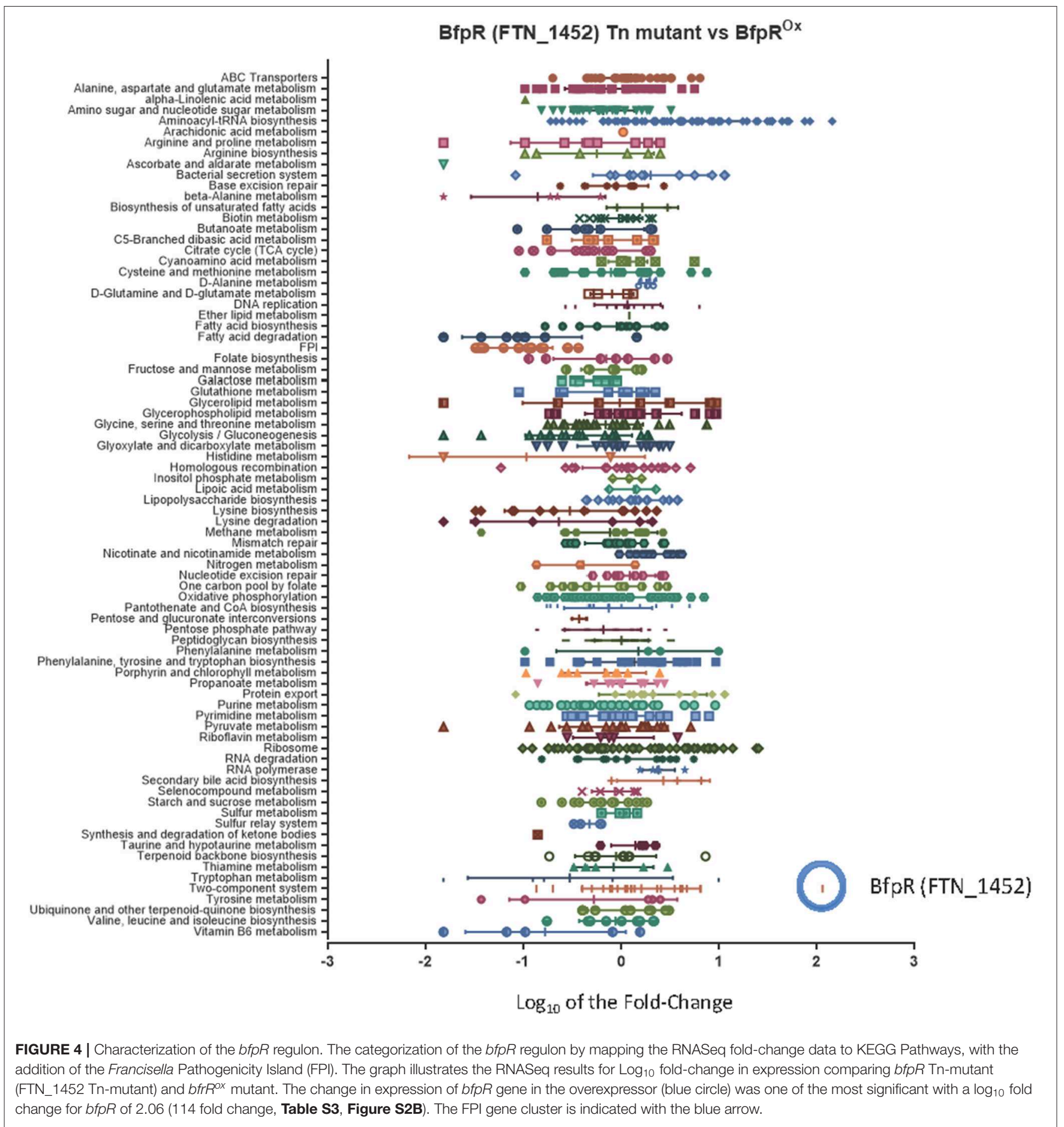

protein expression levels. Proteins of peptidoglycan synthesis as well as Phe, Tyr and Trp biosynthesis proteins were also highly upregulated in $b f p R^{o x}$, as well as cell division-associated proteins. Other comparisons between the proteomic and transcriptomic results show that in addition to the FPI genes and proteins iglA, $i g l B$ and $i g l C$ being strongly down-regulated in $b f p R^{o x}$, many tRNA genes (e.g., FTN_1541, tRNA Arg) are upregulated in in $b f p R^{o x}$, corresponding to the increased expression of Arg, Pro metabolism proteins in the proteomic data.

\section{Effect of $b f p R$ Mutation and Overexpression on Protein Expression}

We next characterized the BfpR "regulon" using proteomic analysis. This method has been previously used to help define the regulon of PhoP in different strains of Salmonella enterica (Charles et al., 2009). The protein expression data shows 342 proteins were dysregulated $\geq 1$. 5 -fold when comparing $b f p R$ and $\mathrm{WT}$, and 413 proteins were up- or down-regulated $\geq 1.5$-fold 
in the $b f p R^{o x}$ strain to $b f p R$ comparison. One hundred seventynine proteins were found to be overlapping between these two comparisons. To further analyze the overlapping region of this dataset, we categorized the proteins by KEGG pathway. Notably, comparing the mutation of $b f p R$ and the complementation back caused a significant change in abundance of FPI proteins, with an average percent decrease of $60 \%$ in the WT vs. $b f p R$ to $b f p R^{o x}$ vs. $b f p R$ comparisons (Figure S2C). Among the many F. novicida proteins that changed by proteomics analysis, $I g l C$ was downregulated by $b f p R^{o x}$, confirmed in the Western Blot data shown below. Acid phosphatase A, AcpA, was reduced in $b f p R$ (2-fold) compared to WT, correlating to the RNASeq data. The level of glucose-1-phosphate adenylyltransferase protein (involved in glycogen synthesis, $\mathrm{GlgC}$ ) was increased (3-fold) in $b f p R$ compared to WT. Thus, unlike the deletion of QseB/PmrA, which positively regulates FPI gene expression and deletion leads to decreased expression of these virulence factors, deletion of $\mathrm{BfpR}$ has little direct effect on protein expression. This suggests that BfpR may be a negative regulator unlike QseB/PmrA. Some proteins (such as $\mathrm{GlgC}$ see below) appear to be positively regulated by $b f p R$ mutation, illustrating the potential complexity of the $b f p R$ regulon.

\section{Putative Target Binding Sequence of BfpR}

We next analyzed the promoters of genes found in the $b f p R$ regulon, choosing WalR as the model response regulator and the F. novicida U112 genome in the program PePPER (de Jong et al., 2012). This led us to identify a putative predicted palindromic binding sequence for BfpR as: TGT- $\mathrm{n}_{8 / 9}-\mathrm{TGT}$, which was identified upstream of multiple BfpR-regulated Francisella genes, including iglA, $g l g C$, and $a c p A$ (Figures S3B, S4). Formal definition of the BfpR binding site will require DNA footprinting assays and EMSA assays, but our computational prediction of a putative binding palindrome allowed us to explore some aspects of potential BfpR-DNA binding.

To test the binding of BfpR to DNA, we established DNAprotein interaction using ELISA and ChIP-PCR with fragments of the acpA promoter. Creating three $\sim 150 \mathrm{bp}$ fragments from -500 to -10 upstream of the start sites, we found through ELISA studies that BfpR-His ${ }_{6}$ binds to the distal region of this promoter (Figure S4A). These results were further indicated by amplification using primers for fragment I in ChiP-PCR experiments (Figure S4B). With both techniques, binding of BfpR-His 6 to other acpA promoter regions was not detected. Circular dichroism experiments of $\mathrm{BfpR}-\mathrm{His}_{6}$ in the presence and absence of acpA promoter fragments further suggested a specific interaction may occur between $\mathrm{BfpR}$ and the distal region of the promoter sequence (Figure S4C). These results are consistent with the predicted TGT- $\mathrm{n}_{8 / 9}$-TGT binding site, found in the distal fragment.

To further evaluate DNA binding, we explored in silico docking of a small DNA fragment to a full-length homology model of BfpR (Figure S3A). HADDOCK (Wassenaar et al., 2012; van Zundert et al., 2016) was used to probe the binding interactions between an acpA promoter fragment $5^{\prime}$ AACTGTTAC and our full-length model of BfpR. The model was generated by combining the crystal structure of the $\mathrm{N}$-terminal domain with other structures of full-length $\mathrm{OmpR} / \mathrm{PhoP}$ family response regulators. HADDOCK clustered 167 structures into 12 clusters. The top scoring cluster based on the HADDOCK score and Z-score clearly places the DNA fragment onto the canonical DNA-binding helix of the BfpR DNA-binding domain (Figure S3B). This cluster has significantly better scores than the next best ranked cluster, indicating that this DNA binding position is the best docking solution. These results suggest that BfpR should bind DNA in a similar manner as other $\mathrm{OmpR} / \mathrm{PhoP}$ response regulators and suggests a putative palindromic sequence.

To confirm the binding of BfpR to a shorter, more specific sequence we generated small DNA fragments containing

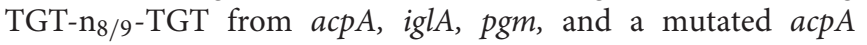
fragment where TGT was replaced by CAC (Figure S4D). DNAprotein interaction ELISA showed that acpA, iglA, and pgm fragments bind $(p<0.01)$ to $\mathrm{BfpR}^{-\mathrm{Hi}_{6}}$, but not the mutated CAC- $\mathrm{n}_{8 / 9}$-CAC fragment (Figure S4E). With the binding sequence better established, we aligned the TGT- $\mathrm{n}_{8 / 9}$-TGT segments of genes found within the BfpR regulon (the set of genes regulated by $\mathrm{BfpR}$ ) identified above to generate the putative consensus sequence: TGT(T/A)X(T/A)XXX(T/A)XXTGT (Figure $\mathbf{S 4 F}$ ) as the putative predicted BfpR binding sequence.

\section{BfpR Is Associated With Regulation of Biofilm Formation}

Response regulators are known to regulate biofilm formation and dispersal in other bacterial systems. Our group has previously showed the positive regulation of biofilm formation by the QseB/PmrA response regulator in F. novicida (Durham-Colleran et al., 2010). Mutation or deletion of QseB/PmrA leads to a significant decrease in biofilm formation. Here, we assessed the role of BfpR in biofilm formation in F. novicida by measuring the ability of WT, $b f p R$, and $b f p R^{o x}$ to form biofilm. Using the crystal violet staining method, biofilm adherence to polystyrene was quantified as in our previous study (Durham-Colleran et al., 2010). The $b f p R$ mutant had a $\sim 5$-fold increase in biofilm formation over WT (Figure 5). The results also indicate that WT and $b f p R^{o x}$ produced statistically equivalent amounts of biofilm after $24 \mathrm{~h}$, which were both much less than the large amount of biofilm produced by the $b f p R$ mutant. The biofilm production of the $g l g C$ transposon-insertion mutant is also demonstrated. The $b f p R$ mutant phenotype is the opposite phenotype than the QseB/PmrA mutation, which showed a decrease in biofilm production.

Because BfpR protein is predicted to bind to pgm-glgC promoter DNA (Figure S4F), we tested whether $b f p R$ mutation influenced the levels of intracellular glycogen and extracellular polysaccharide ( $p g m$ is immediately upstream of $g l g C$ and the two genes are predicted to be in the same operon, sharing the same promoter). We demonstrated that $\mathrm{GlgC}$ protein levels were 3 -fold increased in the $b f p R$ mutant strain (see above). The extracellular level of polysaccharide production from WT, $b f p R$, and $b f p R^{o x}$ was determined by iodine vapor staining. The $g l g C$ transposon-insertion mutant (Gallagher et al., 2007) was used as a control for no glycogen production. Figure S6A shows that 


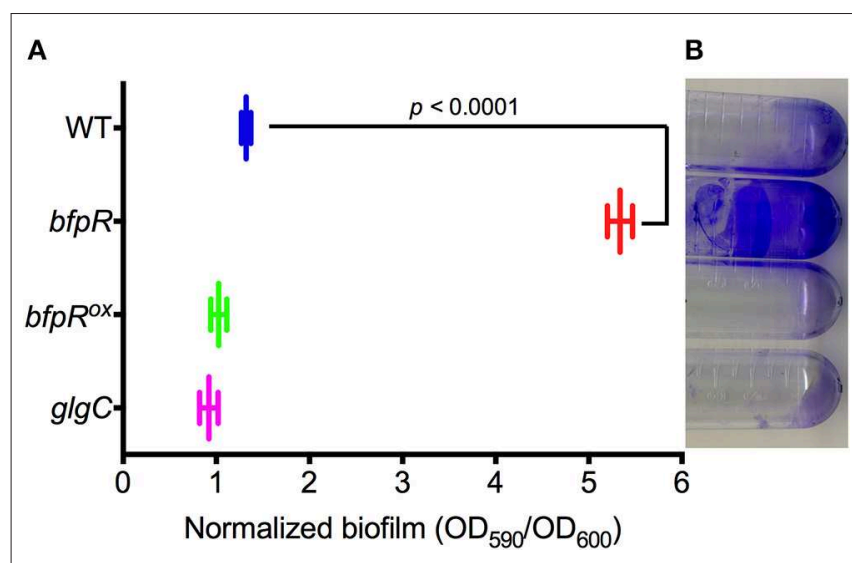

FIGURE 5 | Impact of $b f p R$ on biofilm formation. (A) Quantification of biofilm formation of WT, $b f p R, b f p R^{o x}$, and $g l g C$, measuring crystal violet staining from triplicate experiments. $b f p R$ produced significantly more $(p<0.0001)$ biofilm than WT, bfp $R^{o x}$, and $g / g C$. (B) Representative image of biofilm formation on polystyrene tubes.

$b f p R$ mutation increases the level of polysaccharide formed, while $\mathrm{WT}$ and $b f p R^{o x}$ have lower levels. The staining using iodine is not specific for any one polysaccharide and other macromolecules can complex with iodine, but one of the polysaccharides stained by iodine is glycogen. Next, we quantified the intracellular glycogen levels in WT, $b f p R$, and $b f p R^{o x}$ using a colorimetric glycogen assay. The $g \lg C$ mutant was used as a control for no glycogen production. Figure S6B shows the relative higher glycogen levels in the $b f p R$ mutant, compared to WT and $b f p R^{o x}$. This increased polysaccharide formation could be contributing to the significant increase in biofilm production we observed.

Thus, the $b f p R$ mutant makes more biofilm, more general polysaccharide and more glycogen than wild-type $F$. novicida. The expression of glycogen synthesis genes $g \lg X$ (FTN_0512) and $g l g B$-pgm-glgCAP (FTN_0513-FTN_0517) are altered in response to $b f p R$ overexpression (1.46-fold for $g \operatorname{lgX} ; 0.42$, $0.377,0.145,0.565,0.436$-fold, respectively, for the rest), while pgm (FTN_0514) and $g l g P$ (FTN_0517) were down regulated in the $b f p R$ mutant vs. WT $(0.466$-fold and $0.551-$ fold, respectively). Our results indicated that mutation of $b f p R$ increased biofilm formation and polysaccharide levels, as well as intracellular glycogen, while in $b f p R^{o x}$ these levels were significantly decreased. The regulation of the differently organized $g \lg B X C A P$ operon in E. coli by the PhoP-PhoQ TCS provides evidence of similar regulation in another Gram-negative bacteria (Montero et al., 2011). Both $\operatorname{glgB}$ and $g \operatorname{lgC}$ have been shown to be essential for Francisella lung infection in mice ( $\mathrm{Su}$ et al., 2007), and mutants of $g l g B$ were shown to be attenuated in a Drosophila melanogaster infection model (Ahlund et al., 2010). The connection between the glycogen synthesis genes with biofilm formation and virulence has been established in other Gram-negative organisms (McMeechan et al., 2005; Ito et al., 2009); however, the connection between glycogen synthesis genes, biofilm formation and virulence in Francisella remains to be further characterized.

\section{bfpR Mutation Increases Susceptibility to AMPs and Overexpression Increases AMP Resistance}

Other phenotypes of interest in Francisella include cationic antimicrobial peptide (AMP) resistance (Jones et al., 2012; Li et al., 2012) and intracellular growth (Nano et al., 2004; Jones et al., 2012), each of which has been demonstrated as being under the control of response regulator in other bacteria. Response regulators are known to control resistance to polymyxin $\mathrm{B}$ (cyclic peptide antibiotic) and AMPs, including the response regulators ParR (Fernandez et al., 2010), PhoP (Guina et al., 2000), and PmrA (Gunn and Miller, 1996) in other bacteria. A gene encoding glycosyltransferase (FTN_0545, FlmF2, or yfdH) was found to be significantly deceased ( 0.45 -fold) in expression in the $b f p R$ mutant strain relative to WT (Richards et al., 2008; Wang et al., 2009). This gene is involved in the "biosynthesis of disaccharides, oligosaccharides and polysaccharides" and has sequence homology to ArnC of $P$. aeruginosa, which is annotated as a "putative polymyxin resistance protein" (Song et al., 2009). In $P$. aeruginosa, the arn operon is involved in resistance to peptide antibiotics and cathelicidin AMPs such as the human LL-37, and is regulated by the TCS ParR-ParS (Fernandez et al., 2010). The altered expression of LPS-related genes (Figure 4) in the $b f p R$ mutant and $b f p R$ complemented overexpressing strain $\left(b f p R^{o x}\right)$ is also consistent with the respective increased susceptibility and resistance to cationic AMPs in these two strains.

The effect of AMPs and peptide antibiotics on WT F. novicida and $b f p R$ mutants was tested. $b f p R^{o x}$ was significantly more resistant to AMPs LL-37 and SMAP-29 than WT $(p<0.05)$ (Figure 6). Specifically, the $\mathrm{EC}_{50}$ values (and associated 95 $\%$ confidence intervals) of WT, $b f p R$, and $b f p R^{o x}$ for LL-37 were determined to be $1.0(0.4-2.4), 0.2(0.1-0.8)$, and 3.5 (2.5-5.0) $\mu \mathrm{g} / \mathrm{mL}$, respectively, for SMAP-29 the values were 0.9 (0.5-1.8), $0.5(0.3-0.7)$, and $2.2(0.9-5.3) \mu \mathrm{g} / \mathrm{mL}$, respectively. The $\mathrm{EC}_{50}$ values obtained show significant $\geq 2$-fold shifts in sensitivity and resistance in a BfpR-dependent manner. Our study showed slightly increased susceptibility of $F$. novicida to two potent alpha-helical AMPs (LL-37 and SMAP-29) with $b f p R$ mutation and significantly increased resistance when $b f p R$ was overexpressed.

Francisella species are known to be highly resistant to polymyxin, a drug that is often used as a model of cationic antimicrobial peptide sensitivity. Francisella grown on media containing polymyxin B at $100 \mu \mathrm{g} / \mathrm{ml}$ in the specialized media used to isolate Francisella spp. from environmental samples (Petersen et al., 2009). Francisella that have the mutant $b f p R$ were not found to be more susceptible than WT to cyclic peptide antibiotics such as polymyxin $\mathrm{B}$, while $b f p R^{o x}$ displayed significant resistance to killing (Figure S7). Thus, BfpR may be a positive regulator of AMP-resistance, likely through an indirect mechanism.

To ascertain whether the AMP resistance of $b f p R^{o x}$ was to antibiotics in general, other compounds were tested. We determined that the susceptibility to streptomycin, ciprofloxacin, and gentamicin was not significantly altered by $b f p R$ mutation or overexpression (see Figure S7B). 

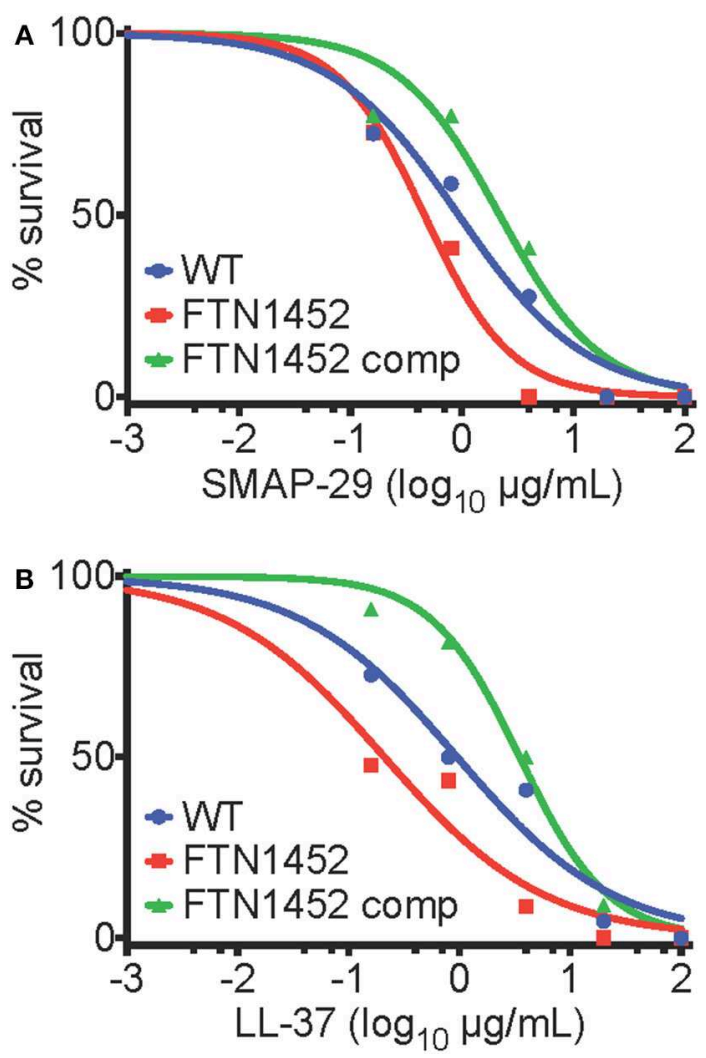

FIGURE 6 | bfpR influences AMP resistance. (A,B) Survival of bacteria with titration of cathelicidin AMPs. (A) $\mathrm{EC}_{50}$ values of $\mathrm{WT}, \mathrm{bfp} R$, and $b f p R^{\circ x}$ with $\mathrm{LL}-37$ were found to be $1.0,0.2$, and $3.5 \mu \mathrm{g} / \mathrm{mL}$, respectively. (B) $E C_{50}$ values of WT, bfpR, and $b f p R^{\text {ox }}$ with SMAP-29 were found to be $0.9,0.5$, and $2.2 \mu \mathrm{g} / \mathrm{mL}$, respectively. Data are shown are a representative of three independent experiments.

\section{High $\mathrm{Mg}^{2+}$ and Response Regulator-Targeting Inhibitor Recovers Growth Inhibited by bfpR Overexpression}

$\mathrm{Mg}^{2+}$ is often sensed via bacterial two-component systems, such as $\mathrm{PhoPQ}$, where under high $\mathrm{Mg}^{2+} \mathrm{PhoQ}$ dephosphorylates PhoP to an inactive state (Groisman, 2001). We assessed the growth of the $b f p R$ mutant and $b f p R^{o x}$ and observed a significant inhibition of growth $(p<0.05)$ from overexpressing $b f p R$ (Figure 7A). Our results show that $\mathrm{Mg}^{2+}$, in high concentrations $(100 \mathrm{mM})$, did not alter the growth of WT or $b f p R$ mutant bacteria (Figure 7B). In the growth deficient $b f p R^{o x}$, however, $\mathrm{Mg}^{2+}$ increased growth back to WT levels in a dose dependent manner (Figure S8). Thus, high $\mathrm{Mg}^{2+}$ released the growth suppression induced by overexpressing $\mathrm{BfpR}$ and relieves the apparent growth defect.

The relationship of the signal $\mathrm{Mg}^{2+}$ and gene regulation via the PhoP-PhoQ TCS has been established in Salmonella typhimurium, E. coli, Yersinia pestis, and P. aeruginosa (Garcia Vescovi et al., 1996; Minagawa et al., 2003; Zhou et al., 2005; McPhee et al., 2006). Although Francisella species do not encode for an obviously homologous PhoP-PhoQ system, $b f p R$ and its adjacent putative sensor kinase $b f p K$ may play a similar role in $F$. novicida signaling. Our growth and kinetic experiments showed that the growth defect of the $b f p R^{o x}$ strain could be relieved by high $\mathrm{Mg}^{2+}$ treatment (similar to the effect of walrycin $\mathrm{A}$, a response regulator-inhibitor, shown below). We have not yet determined whether this $\mathrm{Mg}^{2+}$ effect is directly acting on the $\mathrm{BfpR}$ or is an indirect action on the cognate sensor kinase.

Interestingly, a similar effect was seen using a response regulator-inhibitor found to target $W a l R$ in Gram-positive bacteria, walrycin A (Gotoh et al., 2010). We tested walrycin A (4-methoxy-1-naphthol) and two control naphthol compounds (Figure 7C) for their effect on growth of WT, $b f p R$, and $b f p R^{o x}$. The control compounds, 1-naphthol and 7-methoxy-2-naphthol, differ only slightly from walrycin A in their chemical structure. Walrycin A alone was capable of offsetting the decreased growth of $b f p R^{o x}(p<0.05)$ (Figure 7D).

To explore potential binding of walrycin A to BfpR, computational docking experiments were performed using AutoDock 4.2. Walrycin A, 1-naphthol, and 7-methoxy-2naphthol were each docked to our full-length model of BfpR. The location of the top ranked putative binding pocket (pocket 1) was the same for all three compounds (Figure S9). Pockets 2 and 3 also ranked among the top binding sites across all the compounds. Pockets 1 and 2 are located in the DNA binding domain. Pocket 2 is specifically located at the end of the DNA-binding helix where compound binding could directly impact DNA-binding activity. Pocket 3 is located within the dimerization interface of the $\mathrm{N}$-terminal receiver domain where a compound could disrupt the ability of BfpR to dimerize. From the putative binding interactions identified in these docking simulations, the ability of walrycin A to offset the decrease in $b f p R^{o x}$ growth could be caused by walrycin A binding BfpR at these sites. There is no significant difference between the predicted interactions between $\mathrm{BfpR}$ and walrycin A, 1-naphthol, and 7-methoxy-2-naphthol. This is likely due to the similar structural characteristics of each of these compounds. The predicted binding energy, ligand efficiency (LE), and binding efficiency index (BEI) for each compound in each pocket are shown in Figure S9. Based on these results, walrycin A, 1-naphthol, and 7-methoxy-2-naphthol all have the potential to bind BfpR within the limits of rigid docking experiments.

To confirm these potential binding interactions, we performed differential scanning fluorimetry experiments using BfpR-His 6 with or without walrycin A, 1-naphthol, and 7-methoxy-2naphthol. The results show that a protein population not seen in the presence of the control compounds appears in the presence of walrycin A (Figure 7E). Consistent with the proposed mechanism on WalR (Gotoh et al., 2010), the thermal shift to lower temperatures suggests that the walrycin A-treated BfpR population is destabilized and unfolds at a lower temperature than untreated BfpR.

Using a 2-aminoimidazole-based compound that targets response regulators, we have previously shown that we can inhibit BfmR, a master controller of biofilm in Acinetobacter baumannii (Thompson et al., 2012; Milton et al., 2017), and 

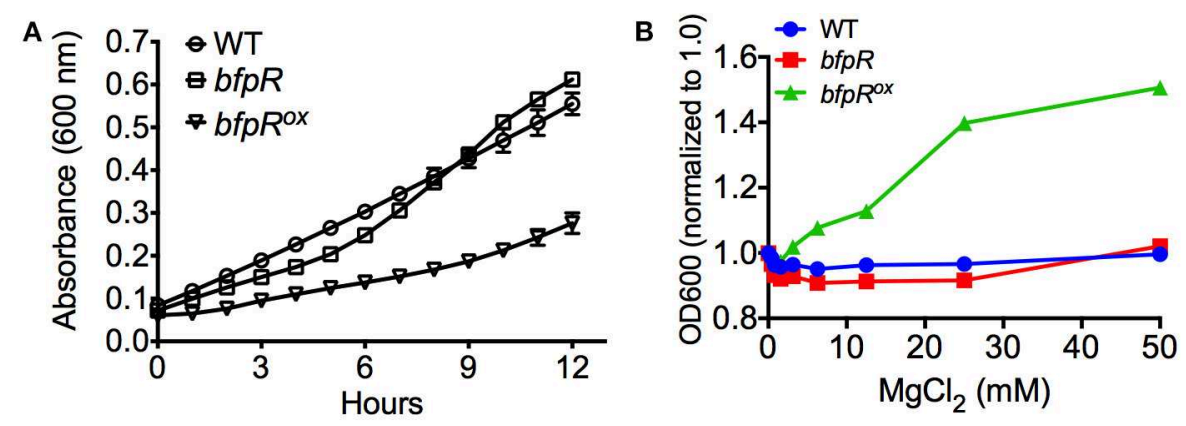

C<smiles>COc1ccc(O)c2ccccc12</smiles>

\section{4-Methoxy-1-naphthol} (walrycin A)

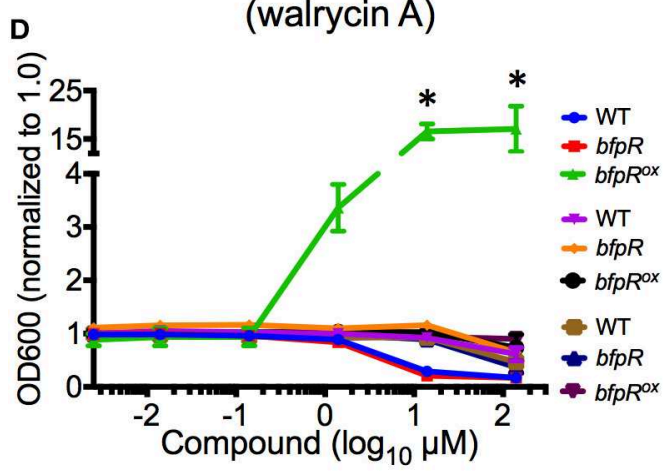<smiles>Oc1cccc2ccccc12</smiles>

1-Naphthol<smiles>COc1ccc2ccc(O)cc2c1</smiles>

7-Methoxy-2-naphthol

E

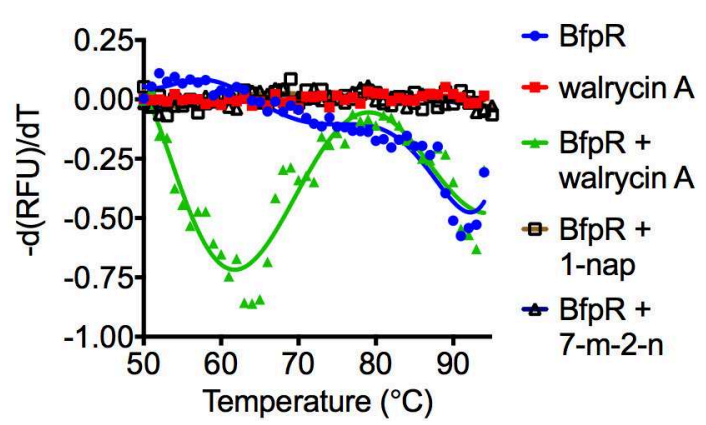

FIGURE $7 \mid b f p R$ overexpression growth defect and growth induction by $\mathrm{Mg}^{2+}$ and inhibitor. (A) The growth rates of WT and bfpR in TSBC. (B) The growth of WT and bfpR in TSBC with increasing concentration of $\mathrm{MgCl}_{2}$. (C) Chemical structures of walrycin A (4-Methoxy-1-naphthol), 1-Naphthol, and 7-Methoxy-2-naphthol are shown. (D) WT, bfpR, and bfpR $R^{o x}$ with a titration of walrycin A (blue, red, green) and control compounds 1-naphthol (purple, orange, black) and 7-Methoxy-2-naphthol (brown, navy blue, and maroon). The data normalized to 1.0 for untreated. (E) Differential scanning fluorimetry using SYPRO Orange was performed on BfpR-His, with and without walrycin A, 1-Naphthol, or 7-Methoxy-2-naphthol. Walrycin A: wal A, 1-Naphthol: 1-nap, 7-ethoxy-2-naphthol: 7-m-2-n. Data are shown as averages from three independent experiments, error bars indicate standard deviation, and significance was determined by Student's $t$-test. ${ }^{*} p<0.001$.

F. novicida QseB (Milton et al., 2017; Draughn et al., 2018). These results suggest that response regulators are a potential therapeutic target. Walrycin A was discovered in a screen by Gotoh et al. to target the WalR response regulator of B. subtilis and S. aureus (Gotoh et al., 2010). In both of these low-GC content Gram-positives, WalR is known to be essential for cell viability, while also regulating biofilm formation, antibiotic resistance, and virulence (Dubrac et al., 2007; Howden et al., 2011). Gotoh et al. determined that walrycin A binds to WalR monomers, inducing the formation of an unstable dimer, altering the structural conformation such that DNA-binding is inhibited (Gotoh et al., 2010). Two of the top predicted walrycin A binding sites also are located in regions that could directly impact DNAbinding and dimerization. The effect on F. novicida appeared to be similar to B. subtilis and S. aureus, as both WT and the $b f p R$ mutant had decreased growth in high concentrations of walrycin A. Conversely, when the $b f p R^{o x}$ was treated with $10 \mu \mathrm{M}$ walrycin $\mathrm{A}$, a 16 -fold increase in growth was observed, suggesting that walrycin $A$ decreases the effect of $B f p R$ repression, enabling growth to WT-levels. These data indicate a potential for response regulator-targeting compounds to control Francisella growth, and other activities modulated by response regulators. The concept of targeting sensor kinases in F. tularensis with an inhibitor has shown potential in a previous study from our group (Rasko et al., 2008).

\section{bfpR Overexpression Inhibits Intramacrophage Replication and Infection in Galleria mellonella}

We assessed the effect of BfpR on intramacrophage replication and virulence in the moth larvae insect model, Galleria mellonella. First, to determine the relative levels of FPI protein expression, we assayed levels of one of the well-studied virulence factors, the FPI protein IglC in WT, $b f p R$, and $b f p R^{o x}$ strains by western blotting. Consistent with our proteomic data, levels of IglC in WT and $b f p R$ were similar to each other, while IglC levels in $b f p R^{o x}$ were significantly decreased (Figure $\mathbf{8 A}$ ). This 

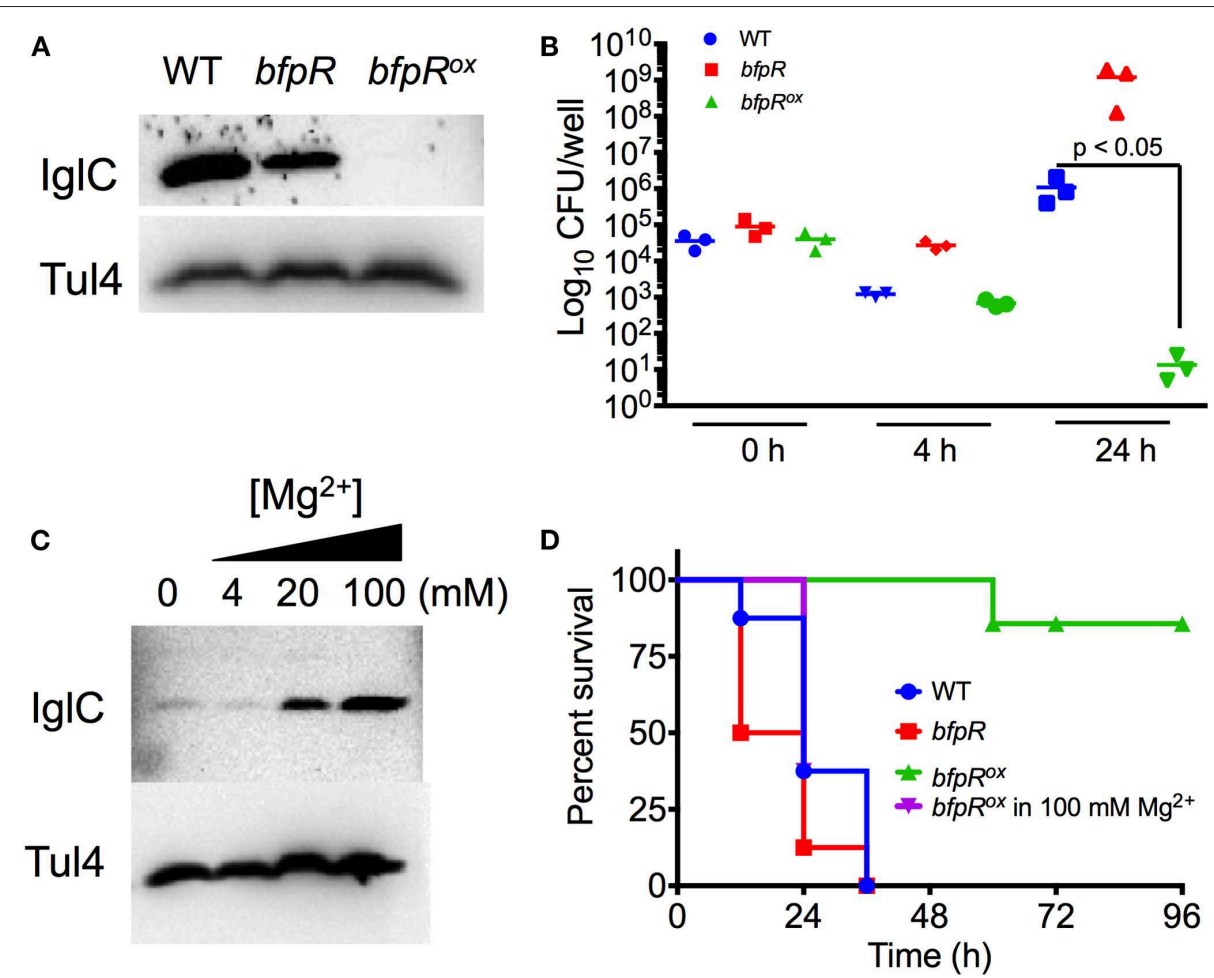

FIGURE 8 | bfpR mutation and overexpression affects intracellular replication and virulence. (A) Western blot for lglC protein expression in WT, bfpR, and bfpRox. (B) Confluent cultures of PMA-differentiated U937 human monocytes were infected (MOI 50). Following the gentamicin protection protocol, CFU was determined. (C) Western blot showing IglC expression in the bfpR ${ }^{\text {ox }}$ with increasing concentrations of $\mathrm{Mg}^{2+}$. Tul4 was probed as a control protein. (D) Galleria mellonella were injected with equal CFUs. Caterpillars were observed twice daily for survival status. Data are shown as averages from three independent experiments and significance was determined by Student's $t$-test or log-rank test. The difference between bfpRox and the wild type is highly significant, $p<0.05$.

response regulator-mediated control of IglC is opposite to the activity shown in previous studies of QseB/PmrA in F. novicida and F. tularensis LVS (Sammons-Jackson et al., 2008; Bell et al., 2010; Durham-Colleran et al., 2010). In those studies, mutants of $q s e B / p m r A$ lead to a decrease in IglC expression. Thus, BfpR may act in the opposite direction with respect to iglC and FPI gene expression than $\mathrm{QseB} / \mathrm{PmrA}$, and be a direct or indirect negative regulator.

Using human-derived U937 macrophages, we infected PMAdifferentiated macrophages at 50 MOI for $2 \mathrm{~h}$ and performed gentamicin protection so that only intracellular Francisella remained. $b f p R$ showed increased intracellular levels of bacteria at 4 and 24 h, compared to WT, while $b f p R^{o x}$ resulted in significantly decreased levels of intracellular bacterial replication after $24 \mathrm{~h}$ $(p<0.05)$ (Figure 8B), consistent with the highly reduced iglC expression but this result may also have been affected by the in vitro growth defect observed (Figure 7).

To assess the effect of $\mathrm{BfpR}$ on $F$. novicida infection, we used the G. mellonella infection model. This model organism has previously been shown to be a useful model of the innate immune system in mammals and has been used as a model host of Francisella infection (Aperis et al., 2007; Ahmad et al., 2010; McKenney et al., 2012; Kaushal et al., 2016). Figure 8D shows that WT and $b f p R$ mutant are similar in pathogenicity to the
Galleria larvae, while the $b f p R^{o x}$ is significantly less pathogenic $(p<0.001)$, causing no killing until $60 \mathrm{~h}$, consistent with highly reduced iglC expression. We conclude that $b f p R$ overexpression reduces virulence of $F$. novicida in this infection model, while $b f p R$ transposon insertion mutant has little effect, suggesting a negative regulation model.

Our previous observations indicated that the addition of $\mathrm{Mg}^{2+}$ may cause de-repression of the BfpR-mediated decrease in growth. To further investigate this de-repression in relation to virulence factor expression, we incubated $b f p R^{o x}$ with a titration of $\mathrm{Mg}^{2+}$ and probed for IglC levels. Our results show a $\mathrm{Mg}^{2+}$ concentration-dependent increase in IglC expression (Figure 8C). To further explore the significance of this result in our infection model, we grew $b f p R^{o x}$ in $100 \mathrm{mM} \mathrm{Mg} \mathrm{Mg}^{2+}$ and again, normalized bacterial number and infected Galleria larvae. After $36 \mathrm{~h}$ the increased virulence of $\mathrm{Mg}^{2+} b f p R^{o x}$ was apparent, with a significantly shorter time-to-death compared to $b f p R^{o x}$ grown without addition of $100 \mathrm{mM} \mathrm{Mg}^{2+}(p<$ $0.001)$, consistent with the de-repression of iglC expression. We hypothesize that the initial growth conditions of the bacteria enable the production of certain virulence factors that enable the Francisella to establish an infection in the waxworm. Thus, BfpR has sensitivity to $\mathrm{Mg}^{2+}$, consistent with its WalR/PhoP classification (Lejona et al., 2003). 
The intricate control of the many physiological activities of Francisella is critical for its ability to survive in the environment and in infected hosts. The BfpR regulon is shown here to exert physiological effects on $F$. novicida, particularly affecting the production of $F$. novicida biofilm and resistance to antimicrobial peptides. BfpR also indirectly or directly negatively modulates expression of some Francisella Pathogenicity Island genes such as $i g l C$, which are necessary for intramacrophage replication and infection. In summary, we conclude that Francisella BfpR is a response regulator of the $\mathrm{OmpR} / \mathrm{PhoP}$ family that negatively regulates the expression of some FPI proteins and biofilm formation and positively regulates resistance to AMPs.

Interestingly, this places $\mathrm{BfpR}$ in opposition with $\mathrm{MglA}$ and QseB/PmrA. The transcriptional regulator $\mathrm{MglA}$ and the response regulator $\mathrm{QseB} / \mathrm{Pmr} \mathrm{A}$ have been shown to be activators of intracellular replication by positively regulating FPI genes (Brotcke et al., 2006; Dai et al., 2010). However, in a recent study, Ramsey and Dove suggest that QseB/PmrA may not directly regulate FPI expression, and it may not positively regulate expression of FPI genes, therefore the direct role of $\mathrm{QseB} / \mathrm{PmrA}$ in regulation of virulence remains unclear (Ramsey and Dove, 2016). Further investigation of these two-component systems may allow for a better understanding of the network of proteins controlling virulence factor expression in F. novicida, the potential activity of protein complexes that include $\mathrm{BfpR}$, as well as the potential for response regulator-targeting compounds that can control or block the function of these critical proteins.

\section{EXPERIMENTAL PROCEDURES}

\section{Bacterial Strains, Plasmids, and Growth Conditions}

The strains and plasmids used in this study are listed (Table S1). F. novicida U112 and $b f p R$ transposon mutant (FTN1452, strain tnfn1_pw060328p04q153) obtained from BEI Resources, NIAID, $\mathrm{NIH}$ ) were grown at $37^{\circ} \mathrm{C}$ in Tryptic Soy Broth with $0.1 \%(\mathrm{w} / \mathrm{v})$ cysteine (TSBC). The $b f p R$ mutant was grown in kanamycin $20 \mu \mathrm{g} / \mathrm{ml}$ in the first passage to ensure presence of the transposon. Escherichia coli was grown in Luria-Bertani (LB) broth or on LB agar. When necessary, antibiotics were added: ampicillin $50 \mu \mathrm{g} / \mathrm{ml}$, kanamycin $20 \mu \mathrm{g} / \mathrm{ml}$ and tetracycline $50 \mu \mathrm{g} / \mathrm{ml}$.

\section{Purifying BfpR N-Terminal Domain}

The BfpR N-terminal domain construct (BfpRN, residues 1129) was cloned into pET28a (Novagen) using NdeI and XhoI restriction sites to generate a protein construct containing a thrombin cleavable N-terminal His 6 affinity tag. Proteins were over-expressed in BL21(DE3) cells (Invitrogen) at $37^{\circ} \mathrm{C}, 120 \mathrm{rpm}$ in LB. At an $\mathrm{OD}_{600}$ of $\sim 0.7$, cells were induced with $1 \mathrm{mM}$ isopropyl $\beta$-D-thiogalactopyranoside (IPTG) at $16^{\circ} \mathrm{C}$, overnight. Harvested cell pellets were stored at $-80^{\circ} \mathrm{C}$ for later use. Pellets were resuspended in lysis buffer $(25 \mathrm{mM}$ Tris $\mathrm{pH} 7.8,500 \mathrm{mM}$ $\mathrm{NaCl}, 5 \mathrm{mM}$ imidazole, and $0.1 \mathrm{mM}$ of AEBSF). Cells were sonicated and the resulting lysate clarified at $15,000 \mathrm{rpm}$ for $20 \mathrm{~min}$. The clarified lysate was loaded onto $10 \mathrm{~mL}$ of Ni-NTA resin (QIAGEN) pre-equilibrated in lysis buffer. Ni-NTA-bound protein was subsequently washed with 10 column volumes of lysis buffer followed by 10 column volumes of $20 \mathrm{mM}$ Tris $\mathrm{pH}$ $7.8,1 \mathrm{M} \mathrm{NaCl}$, and $5 \mathrm{mM}$ imidazole. The protein was eluted with a linear gradient from lysis buffer to elution buffer $(25 \mathrm{mM}$ Tris $\mathrm{pH}$ 7.9, $500 \mathrm{mM} \mathrm{NaCl}$, and $300 \mathrm{mM}$ imidazole). Fractions containing protein were pooled. The affinity tag was then cleaved by 100 units of thrombin for $2 \mathrm{~h}$ at room temperature. Cleavage was quenched with $0.1 \mathrm{mM}$ AEBSF. The sample was concentrated and further purified using a S100 26/60 size exclusion column (GE Healthcare) equilibrated in $20 \mathrm{mM}$ Tris pH 7.8 and $400 \mathrm{mM}$ $\mathrm{NaCl}$. Fractions containing the purest protein based on SDSPAGE analysis were pooled and concentrated to $6.7 \mathrm{mg} \mathrm{mL}^{-1}$. Protein was stored at $4^{\circ} \mathrm{C}$ for use in crystallography experiments.

\section{Crystallization and Structure Determination}

BfpRN crystals were grown through hanging-drop vapor diffusion against $0.2 \mathrm{M}$ calcium chloride, 0.1 M HEPES $\mathrm{pH} 7.5$, and $28 \%$ polyethylene glycol 400 at room temperature. Crystals grew at $6.7 \mathrm{mg} \mathrm{mL}^{-1}$ with a protein to cocktail ratio of $1: 1$. Crystals were cryoprotected using $30 \%$ glycerol prior to flash freezing with liquid nitrogen. Data was collected at a wavelength of $1.0332 \AA$ at APS beamline 23-ID (GM/CA). Diffraction was indexed, merged, and scaled using HKL2000 (Otwinowski and Minor, 1997). Molecular replacement was carried out in PhaserMR within the PHENIX suite (McCoy et al., 2007; Adams et al., 2010) using our QseBN structure (PDB ID 5UIC) (Milton et al., 2017) as a starting model. The resulting solution was further refined using COOT (Emsley and Cowtan, 2004) and phenix.refine (Adams et al., 2010). Statistics for data collection and refinement are in Table S2. All structure figures were produced using PyMOL (Schrodinger, 2010).

\section{Construction of Complemented Mutant Overexpressing bfpR}

To obtain the $B f p R$ gene from WT $F$. novicida U112 cDNA, PCR was performed using forward and reverse primers with the Qiagen HotStarTaq Plus Master Mix Kit (Qiagen). The PCR product was cleaved with PstI and EcoRI (New England Biolabs), run on $1 \%$ TAE agarose gel and extracted using the QIAquick Gel Kit (Qiagen). The JSG2845 vector contains a F. tularensis LVS groEL promoter in front of pmrA (Mohapatra et al., 2007). The pmrA gene was removed, a multicloning site was added containing PstI and EcoRI, and BfpR was inserted. The plasmid was ligated with T4 DNA ligase (Promega) following manufacturer's instructions. Following ligation, the plasmid was transformed into NEB 5-alpha competent cells (New England Biolabs), and plated on LB agar $(10 \mu \mathrm{g} / \mathrm{mL}$ tetracycline). The plasmid was purified using the Qiagen Spin MiniPrep Kit (Qiagen) and sequenced (Macrogen USA, Maryland). Electroporation of the $b f p R$ transposon mutant was performed as previously described (Maier et al., 2004). An overnight culture of $b f p R$ mutant was pelleted, washed three times in $0.5 \mathrm{M}$ sucrose, and pipetted into the electroporation cell $(0.2 \mathrm{~cm})$ and was electroporated (GenePulser II (Bio-Rad, California, US); $600 \mathrm{ohm}, 2.5 \mathrm{kV}, 25 \mu \mathrm{F}$ ). Electroporated samples were plated (TSBC, $10 \mu \mathrm{g} / \mathrm{mL}$ tetracycline). This method was 
used for both the untagged $\mathrm{BfpR}$ complemented overexpressing $\left(b f p R^{o x}\right)$ and the BfpR-His 6 -tagged strains (Table S1).

\section{Purifying BfpR Protein}

The $B f p R$ gene was inserted into a protein expression vector for purification. PCR amplification of $b f p R$ DNA was done from $F$. novicida U112 cDNA using specific primers in Table 1. The product was inserted into pTrcHis II TOPO (TOPO TA cloning kit, Invitrogen) and transformed into E. coli One Shot ${ }^{\circledR}$ TOP10 Chemically Competent cells (Life Technologies, Invitrogen). Positive transformant cells were selected with ampicillin $(50 \mu \mathrm{g} / \mathrm{ml})$ on LB agar and verified by PCR using the Xpress forward primer (Invitrogen). Expression of BfpR in cultures was induced by IPTG $(1 \mathrm{mM})$ for $6-8 \mathrm{~h}$ and the $\mathrm{His}_{6}$ tagged protein was purified using $\mathrm{Ni}^{2+}$-NTA resin (Clontech) and eluted with imidazole. Protein was dialyzed with PBS, lyophilized and frozen until use.

\section{LC-MS/MS Proteomic Analysis}

Whole cell lysates from WT F. novicida, $b f p R$, and $b f p R^{o x}$ were prepared (Figure S5). Tryptic peptides were analyzed by reverse-phase liquid chromatography with nanospray tandem mass spectrometry using a LTQ linear ion trap mass spectrometer (Thermo Electron Corporation) and fused silica capillary column $(100 \mu \mathrm{m} \times 10 \mathrm{~cm}$; Polymicro Technologies) with a laser-pulled C-18 tip ( $5 \mu \mathrm{m}, 200-\AA ̊$ pore size; Michrom Bioresources Inc.). After injection, the column was washed $(5 \mathrm{~min}$ mobile phase A $(0.4 \%$ acetic acid), and peptides were eluted using a linear gradient of $0 \%$ mobile phase B $(0.4 \%$ acetic acid and $80 \%$ acetonitrile) to $50 \%$ mobile phase B ( $30 \mathrm{~min}, 0.25 \mu \mathrm{l} / \mathrm{min}$ ) and then to $100 \%$ mobile phase B $(5 \mathrm{~min})$. The LTQ mass spectrometer was operated in a data-dependent mode, where each full mass spectrometric scan was followed by five tandem mass spectrometric scans, in which the five most abundant molecular ions were dynamically selected for collision-induced dissociation using a normalized collision energy of $35 \%$. Tandem mass spectra were searched against the F. novicida U112 NCBI database with SEQUEST (Pierson et al., 2011).

\section{Analysis of Proteomic Data and Promoters}

Spectral counting was used to compare relative changes in protein abundance. Average protein expression was analyzed by using the biological significance limit of 1.5 -fold up-regulation and 0.66 -fold down-regulation from the comparisons of both WT vs. $b f p R$ and $b f p R^{o x}$ vs. $b f p R$. Proteins that were not present in any one of the samples (WT, $b f p R$ mutant, or $b f p R^{o x}$ ) were excluded from the analysis. For categorization of up and downregulated proteins, modules of the KEGG database were used, with some additions for clarity (adherence and FPI). Analysis of promoters of genes found in the BfpR regulon were performed using PePPER (de Jong et al., 2012), leading us to identify the putative binding sequence as: TGT- $\mathrm{n}_{8 / 9}-\mathrm{TGT}$.

\section{ELISA}

The ELISA method for detection of protein-DNA interactions has been previously described (Brand et al., 2010; Liu et al., 2011; Zhang et al., 2013). The ELISA was performed by using pH 9.4 sodium bicarbonate buffer to coat the surface of an EIA/RIA (96well) medium binding polystyrene plate (Corning, NY, US) with BfpR-His $_{6}$ at $3 \mu \mathrm{M}$ or BSA in $100 \mu \mathrm{L}$ of buffer. Following $3 \mathrm{~h}$ incubation at RT, the plate was washed three times. The plate was then blocked with poly $(\mathrm{dI}-\mathrm{dC})$ at $10 \mathrm{ng} / \mu \mathrm{L}, 1 \mathrm{~h}$. After washing, biotinylated promoter fragments were incubated, $1 \mathrm{~h}$. After $3 \mathrm{x}$ washing, rabbit anti-biotin HRP conjugate antibody (Abcam) was added at 1:10,000, $1 \mathrm{~h}$. After washing, 1-Step Turbo TMB solution (Pierce) was added, $15 \mathrm{~min}$. The reaction was stopped and read at $450 \mathrm{~nm}$ using a BioTek microplate reader (Vermont, United States). Data is shown with BSA control values subtracted.

\section{Molecular Modeling of Full Length BfpR}

A full-length model of BfpR was generated using MODELER v9.12 (Eswar et al., 2006). The model was constructed using the crystal structure of the N-terminal domain of BfpR and homologs PhoP from Mycobacterium tuberculosis (PDB ID 3R0J) (Menon and Wang, 2011), PmrA from Klebsiella pneumoniae (PDB IDs 4S04 and 4S05) (Lou et al., 2015), KdpE from E. coli (PDB IDs $4 \mathrm{KFC}$ and $4 \mathrm{KNY}$ ) (Narayanan et al., 2014), and the receiver domain of QseB from F. novicida (PDB ID 5UIC) (Milton et al., 2017). Five hundred models were generated from the sequence alignment of the above-mentioned protein structures with BfpR. Resulting models were scored based on the normalized DOPE (zDOPE) method (Eswar et al., 2006). The structure with the lowest zDOPE score was subsequently run through MolSoft ICM Full Model Builder to generate a fully refined model (MolSoft LLC). Finally, the model was run through PROCHECK and PSVS to evaluate the quality of the model [https://www.ebi.ac.uk/ thornton-srv/software/PROCHECK/ and (Bhattacharya et al., 2007)]. The "best" model had the lowest zDOPE score, highest percentage of favored and allowed Ramachandran regions, and lowest MolProbity clash score.

\section{BfmR-DNA Binding Simulations}

Duplex DNA containing the acpA promoter fragment sequence $5^{\prime}$-AACTGTTAC was generated using the 3D-DART webserver (van Dijk and Bonvin, 2009). The full-length homology model of BfpR and DNA were input into the HADDOCK webserver (Wassenaar et al., 2012; van Zundert et al., 2016). K178, E198, R205, T219, and 2 G219 were set as active residues and V199 and R203 were set as passive residues for BfpR based on homology to the DNA bound structure of PmrA (PDB ID 4S04) (Lou et al., 2015). For the DNA, C2 was set as a passive residue and T4, G5, and T6 were set as passive based on hydrogen bonding observed in the PmrA structure. The highest ranked cluster was selected based on criteria established by HADDOCK.

\section{ChIP-PCR}

The BfpR-His 6 plasmid was transformed into the $b f p R$ mutant. The transformant was grown up in $40 \mathrm{~mL}$ of TSBC with $10 \mu \mathrm{g} / \mathrm{mL}$ of tetracycline overnight. The bacterial culture was fixed with $1 \%$ formaldehyde for $1 \mathrm{~h}$ at RT. The cells were then pelleted at $3,000 \times \mathrm{g}$ for $10 \mathrm{~min}$ and $2 \mathrm{~mL}$ of PBS was added to solubilize the pellet. This was then lysed with freeze/thaw repeated three times. The lysate was sonicated three by $10 \mathrm{~s}$, in $1 \mathrm{~min}$ intervals on ice. Lysate was incubated with $500 \mu \mathrm{L}$ of $\mathrm{Ni}$ 
resin at RT for $30 \mathrm{~min}$. The resin was washed and eluted from using imidazole buffers as described in the QIAexpressionist protocol (Qiagen). Using the eluted solution PCR was performed using the (reverse primers are $5^{\prime}$ biotinylated) primers for the promoter of acpA (fragments I, II, and III). The ORF of FTN1340 $(a c p P)$ was used as a negative control.

\section{Circular Dichroism}

CD spectra were collected using a Jasco J-815 spectropolarimeter with a $0.1 \mathrm{~cm}$ path-length cuvette. Spectra were recorded from 220 to $280 \mathrm{~nm}$ in 2-nm steps in $10 \mathrm{mM}$ sodium phosphate $(\mathrm{pH}$ $7.4,25^{\circ} \mathrm{C}$ ) on samples of BfpR-His 6 and the acpA promoter regions ( -500 to $-337,-356$ to -177 , and -198 to $-10 \mathrm{bp}$ ). Three scans were taken per sample and averaged. Samples were at a concentration of $50 \mu \mathrm{g} / \mathrm{mL}$ of BfpR-His 6 and $10 \mu \mathrm{g} / \mathrm{mL}$ of DNA.

\section{RNAseq}

RNA was prepared using the Qiagen RNeasy Mini Kit. RNA samples were sent to Otogenetics (Georgia, US) for sequencing. Sequencing data (fastq) of each of the samples was mapped against the F. novicida U112 genome (NC_008601, available at NCBI http://www.ncbi.nlm.nih.gov/genome/?term= NC_008601). Mapped data sets were input into BEDtools to determine the hits counts on each of the regions defined in NC_008601. Hits counts of samples were used as input to edgeR (Robinson et al., 2010) for differential gene expression analysis, where the CPM (count per million), $P$-value, and FDR were calculated using Exact test in edgeR, with biological coefficient of variation $(\mathrm{BCV})$ set to 0.1 . A false discovery rate $(\mathrm{FDR})<0.05$ was considered as significantly different. For the WT sample, $12,547,978$ reads were obtained. For the BfpR mutant, 10,523,222 reads were obtained as a combined data set from 2 runs, for the complemented overexpression strain $\mathrm{BfpR}^{\text {ox }}, 12,516,440$ reads were obtained. These resulting data were then subjected to analysis similar to that described in Analysis of proteomic data and promoters methods above, with cutoff of [log2FC] $>2$.

\section{Differential Scanning Fluorimetry}

DSF experiments were carried out as previously described (Niesen et al., 2007). Control heating and fluorescence record was done with CFX96 Realtime and C1000 Thermal Cycler (Bio-Rad, California, US). Five micrometers BfpR-His 6 was loaded into hard shell 96-well PCR plates with transparent film covers (Bio-Rad California, US), with 2X SYPRO Orange (Sigma, Missouri, US). Heat gradients were carried out to $95^{\circ} \mathrm{C}$. Fluorescence was analyzed in the presence or absence of walrycin A (4-methoxy-1-naphthol), 7-methoxy-2-naphtol (Santa Cruz Biotech, California, US), or 1-naphthol (Sigma, Missouri, US). Unfolding at lower temperatures, relative to control samples, indicates destabilization.

\section{BfpR-Small Molecule Docking Simulations}

Walrycin A, 1-naphthol, and 7-methoxy-2-naphthol were docked to our full-length model of BfpR using AutoDock 4.2 (Morris et al., 2009). One hundred poses were searched against the BfpR model and clustered using default AutoDock 4.2 settings for the genetic algorithm, with the maximum number of evaluations set to long (25,000,000 evaluations). Top-ranking clusters were analyzed based on binding energy, ligand efficiency, and binding efficiency index and visualized using PyMol.

\section{Susceptibility to AMPs}

Susceptibility to AMPs was assessed using previous described methods for $\mathrm{EC}_{50}$ determination (Han et al., 2008; Amer et al., 2010). All peptides were synthesized by ChinaPeptides, Inc., (Shanghai, China) using Fmoc chemistry. Peptides were provided at $>95 \%$ purity; structure and purity were confirmed via RPHPLC and ESI-MS. Briefly, AMPs were serially diluted in $10 \mathrm{mM}$ sodium phosphate ( $\mathrm{pH}$ 7.2). Bacteria were added to each well and incubated for $3 \mathrm{~h}$ at $37^{\circ} \mathrm{C}$ with $5 \% \mathrm{CO}_{2}$. Samples were then serially diluted and plated on TSBC agar plates as previously described (Dean et al., 2011). Colonies were counted and EC $_{50}$ values were calculated using GraphPad Prism software (version 6) for Mac OS (GraphPad Software, San Diego, CA).

\section{Biofilm Formation}

Overnight cultures of bacteria were diluted 1:30 into $20 \mathrm{~mL}$ of TSBC. $200 \mu \mathrm{L}$ was added to each well of a 96 well plate (BD Falcon 353072). After $24 \mathrm{~h}$ at $37^{\circ} \mathrm{C}$, the optical densities (OD) of the wells were taken at $600 \mathrm{~nm}$ to normalize for growth, then the liquid was removed by washing with tap water as previously described (O'Toole, 2011). Plates were then incubated at $70^{\circ} \mathrm{C}, 1 \mathrm{~h}$ and stained with $0.1 \%(\mathrm{w} / \mathrm{v})$ crystal violet, $15 \mathrm{~min}$. The stain was removed and previous wash step was repeated. Stain was solubilized out from the biofilm by adding $200 \mu \mathrm{L}$ of $30 \%(\mathrm{v} / \mathrm{v})$ acetic acid and absorbance was read at $590 \mathrm{~nm}$ with a microplate reader. Observation of biofilm formation in test tubes was performed similarly. 1:30 dilutions of overnight cultures were carried out into $3 \mathrm{~mL}$ of TSBC. After growth at $24 \mathrm{~h}$ at $37^{\circ} \mathrm{C}$, absorbance at $600 \mathrm{~nm}$ was taken. Bacteria were removed, tubes were washed, and then stained with $0.1 \%(\mathrm{w} / \mathrm{v})$ crystal violet. The stain was removed, tubes were washed, and pictures were taken with a Perfection 2,480 PHOTO scanner (Epson).

\section{Western Blots}

To determine IglC protein expression, WT, $b f p R$, and $b f p R^{o x}$ were grown overnight in TSBC, bacterial number normalized by OD600 and pellets lysed with BPER (Pierce). Protein concentration was determined by BCA assay. Samples were run on $4-20 \%$ SDS-PAGE and transferred to nitrocellulose, probed with mouse monoclonal antibodies to IglC (NR-3196) and Tul4 (NR-29019, BEI Resources, Manassas, VA) followed by HRP-conjugated goat anti-mouse secondary antibody and developed by SuperSignal West Femto Chemiluminescent Substrate (Pierce). To determine $\mathrm{Mg}^{2+}$-dependent IglC protein expression in $b f p R^{o x}$, the same protocol was followed but with addition varying $\mathrm{MgCl}_{2}$ concentrations during growth.

\section{Intracellular Replication Assays}

The U937 cell line (CRL-1593.2), derived from human macrophages, was used to determine intracellular replication activity. Cells were cultivated in RPMI 1640 medium (Thermo) supplemented with $10 \%$ heat-inactivated fetal bovine serum 
(Gibco). One percentage of penicillin-streptomycin (Gibco) was added during initial cultivation. $1 \times 10^{7}$ cells in $30 \mathrm{~mL}$ RPMI in $75 \mathrm{~cm}^{2}$ flasks were incubated at $37^{\circ} \mathrm{C}$ with $5 \% \mathrm{CO}_{2}$. Experiments were not performed on cells passaged more than 30 times. For infections, cells $\left(1 \times 10^{6}\right.$ cells/well in 24 well plates) were differentiated for $24 \mathrm{~h}$ using phorbol 12-myristate 13-acetate (PMA) (Sigma, Missouri, US). The differentiated cells were washed with PBS and fresh media was added. Bacteria were added at $50 \mathrm{MOI}$ for $2 \mathrm{~h}$ by spinfection. Cells were washed with PBS and fresh media was added with $20 \mu \mathrm{g} / \mathrm{mL}$ gentamicin (Fisher Chemical) and incubated for $1 \mathrm{~h}$. The cells were then washed again and media was replaced with RMPI containing $2 \mu \mathrm{g} / \mathrm{mL}$ gentamicin. Intracellular replication kinetics were determined by lysing with $0.1 \%$ deoxycholic acid (Sigma, Missouri, US) in PBS and plating on TSBC agar plates. The assays were performed in triplicate (3 wells per strain) and repeated three independent times.

\section{Galleria mellonella Infection Model}

Galleria mellonella larvae were obtained from Vanderhorst Wholesale (Saint Marys, OH, USA). Eight to twelve caterpillars of equal size/weight were randomly assigned to each group. Prior to injection, overnight bacterial cultures were normalized to an OD600 of 0.1. Cultures were also plated to confirm viability. A $1 \mathrm{~mL}$ tuberculin syringe was used to inject $10[[$ Inline Image $] \mu \mathrm{L}$ of bacteria into the hemocoel of each caterpillar. For $\mathrm{Mg}^{2+}$ injection, $10 \mu \mathrm{L}$ of $1 \mathrm{M} \mathrm{MgCl}_{2}$ (Sigma, Missouri, US) was injected. Control groups included injection with $\mathrm{PBS}$ and $\mathrm{MgCl}_{2}$ only. The insects were then observed daily for their survival status. Three independent experiments were performed.

\section{Statistical Analysis}

All statistical tests were performed using GraphPad Prism software (version 6) for Mac OS (GraphPad Software, San Diego, CA). A $P<0.05$ was considered to be significant. In some cases, data are included with a 95\% confidence interval, which

\section{REFERENCES}

Adams, P. D., Afonine, P. V., Bunkoczi, G., Chen, V. B., Davis, I. W., Echols, N., et al. (2010). PHENIX: a comprehensive python-based system for macromolecular structure solution. Acta Crystallogr. D Biol. Crystallogr. 66, 213-221. doi: 10.1107/S0907444909052925

Ahlund, M. K., Ryden, P., Sjostedt, A., and Stoven, S. (2010). Directed screen of Francisella novicida virulence determinants using drosophila melanogaster. Infect. Immun. 78, 3118-3128. doi: 10.1128/IAI.00146-10

Ahmad, S., Hunter, L., Qin, A., Mann, B. J., and van Hoek, M. L. (2010). Azithromycin effectiveness against intracellular infections of Francisella. BMC Microbiol. 10:123. doi: 10.1186/1471-2180-10-123

Amer, L. S., Bishop, B. M., and van Hoek, M. L. (2010). Antimicrobial and antibiofilm activity of cathelicidins and short, synthetic peptides against Francisella. Biochem. Biophys. Res. Commun. 396, 246-251. doi: 10.1016/j.bbrc.2010.04.073

Aperis, G., Fuchs, B. B., Anderson, C. A., Warner, J. E., Calderwood, S. B., and Mylonakis, E. (2007). Galleria mellonella as a model host to study infection by the Francisella tularensis live vaccine strain. Microbes Infect. 9, 729-734. doi: 10.1016/j.micinf.2007.02.016

Bell, B. L., Mohapatra, N. P., and Gunn, J. S. (2010). Regulation of virulence gene transcripts by the Francisella novicida orphan response regulator PmrA: role is a similar level of significance. The Kaplan-Meier curve and log-rank test was used to graph and analyze the caterpillar infection experiments. The Student's $t$-test was used in each other case.

\section{DATA AVAILABILITY STATEMENT}

This article contains previously unpublished data. The structure of BfpRN has been deposited to the Protein Data Bank with PDB entry ID 6ONT.

\section{AUTHOR CONTRIBUTIONS}

$\mathrm{MH}$ and SD conceived the original study. SD performed experiments. JC and MM designed and performed the experiments to solve the RR structure and the RR modeling experiments. All authors contributed to the writing of the manuscript.

\section{ACKNOWLEDGMENTS}

We acknowledge Weidong Zhou for LC-MS/MS analysis, Ezra Myung-Chul Chung for technical assistance with some experiments, and Benjamin Bobay for early work on this project. Christopher Hitt assisted with some data analysis. This work was supported in part by NIH grant RO1 GM055769 (JC) and the V Foundation for Cancer Research (JC). Crystallographic data were collected at General Medical Sciences and Cancer Institute's Structural Biology Facility (GM/CA) 23-ID beam line at the Advanced Photon Source, Argonne National Laboratory.

\section{SUPPLEMENTARY MATERIAL}

The Supplementary Material for this article can be found online at: https://www.frontiersin.org/articles/10.3389/fcimb. 2020.00082/full\#supplementary-material

of phosphorylation and evidence of MglA/SspA interaction. Infect. Immun. 78, 2189-2198. doi: 10.1128/IAI.00021-10

Bhattacharya, A., Tejero, R., and Montelione, G. T. (2007). Evaluating protein structures determined by structural genomics consortia. Proteins 66, 778-795. doi: $10.1002 /$ prot.21165

Bourret, R. B. (2010). Receiver domain structure and function in response regulator proteins. Curr. Opin. Microbiol. 13, 142-149. doi: 10.1016/j.mib.2010.01.015

Brand, L. H., Kirchler, T., Hummel, S., Chaban, C., and Wanke, D. (2010). DPIELISA: a fast and versatile method to specify the binding of plant transcription factors to DNA in vitro. Plant Methods 6:25. doi: 10.1186/1746-4811-6-25

Brotcke, A., Weiss, D. S., Kim, C. C., Chain, P., Malfatti, S., Garcia, E., et al. (2006). Identification of MglA-regulated genes reveals novel virulence factors in Francisella tularensis. Infect. Immun. 74, 6642-6655. doi: 10.1128/IAI.01 250-06

Charles, R. C., Harris, J. B., Chase, M. R., Lebrun, L. M., Sheikh, A., LaRocque, R. C., et al. (2009). Comparative proteomic analysis of the PhoP regulon in Salmonella enterica serovar typhi versus typhimurium. PLoS ONE 4:e6994. doi: 10.1371/journal.pone.0006994

Dai, S., Mohapatra, N. P., Schlesinger, L. S., and Gunn, J. S. (2010). Regulation of Francisella tularensis virulence. Front. Microbiol. 1:144. doi: 10.3389/fmicb.2010.00144 
de Jong, A., Pietersma, H., Cordes, M., Kuipers, O. P., and Kok, J. (2012). PePPER: a webserver for prediction of prokaryote promoter elements and regulons. BMC Genomics 13:299. doi: 10.1186/1471-2164-13-299

Dean, R. E., Ireland, P. M., Jordan, J. E., Titball, R. W., and Oyston, P. C. (2009). RelA regulates virulence and intracellular survival of Francisella novicida. Microbiology 155, 4104-4113. doi: 10.1099/mic.0.031021-0

Dean, S. N., Bishop, B. M., and van Hoek, M. L. (2011). Susceptibility of Pseudomonas aeruginosa biofilm to alpha-helical peptides: D-enantiomer of LL-37. Front. Microbiol. 2:128. doi: 10.3389/fmicb.2011.00128

Dennis, D. T., Inglesby, T. V., Henderson, D. A., Bartlett, J. G., Ascher, M. S., Eitzen, E., et al. (2001). Tularemia as a biological weapon: medical and public health management. JAMA 285, 2763-2773. doi: 10.1001/jama.285.21.2763

Draughn, G. L., Milton, M. E., Feldmann, E. A., Bobay, B. G., Roth, B. M., Olson, A. L., et al. (2018). The structure of the biofilm-controlling response regulator BfmR from Acinetobacter baumannii reveals details of its DNAbinding mechanism. J. Mol. Biol. 430, 806-821. doi: 10.1016/j.jmb.2018.02.002

Dubrac, S., Boneca, I. G., Poupel, O., and Msadek, T. (2007). New insights into the WalK/WalR (YycG/YycF) essential signal transduction pathway reveal a major role in controlling cell wall metabolism and biofilm formation in Staphylococcus aureus. J. Bacteriol. 189, 8257-8269. doi: 10.1128/JB.00645-07

Durham-Colleran, M. W., Verhoeven, A. B., and van Hoek, M. L. (2010). Francisella novicida forms in vitro biofilms mediated by an orphan response regulator. Microb. Ecol. 59, 457-465. doi: 10.1007/s00248-009-9586-9

Emsley, P., and Cowtan, K. (2004). Coot: model-building tools for molecular graphics. Acta Crystallogr. D Biol. Crystallogr. 60, 2126-2132. doi: $10.1107 /$ S0907444904019158

Enstrom, M., Held, K., Ramage, B., Brittnacher, M., Gallagher, L., and Manoil, C. (2012). Genotype-phenotype associations in a nonmodel prokaryote. MBio 3:00001-12. doi: 10.1128/mBio.00001-12

Eswar, N., Webb, B., Marti-Renom, M. A., Madhusudhan, M. S., Eramian, D., Shen, M. Y., et al. (2006). Comparative protein structure modeling using modeller. Curr. Protoc. Bioinformatics 15, 5.6.1-5.6.30. doi: 10.1002/0471250953.bi0506s15

Fernandez, L., Gooderham, W. J., Bains, M., McPhee, J. B., Wiegand, I., and Hancock, R. E. (2010). Adaptive resistance to the last hope antibiotics polymyxin B and colistin in Pseudomonas aeruginosa is mediated by the novel two-component regulatory system ParR-ParS. Antimicrob. Agents Chemother. 54, 3372-3382. doi: 10.1128/AAC.00242-10

Gallagher, L. A., Ramage, E., Jacobs, M. A., Kaul, R., Brittnacher, M., and Manoil, C. (2007). A comprehensive transposon mutant library of Francisella novicida, a bioweapon surrogate. Proc. Natl. Acad. Sci. U.S.A. 104, 1009-1014. doi: $10.1073 /$ pnas. 0606713104

Gao, R., and Stock, A. M. (2009). Biological insights from structures of two-component proteins. Annu. Rev. Microbiol. 63, 133-154. doi: 10.1146/annurev.micro.091208.073214

Garcia Vescovi, E., Soncini, F. C., and Groisman, E. A. (1996). Mg2+ as an extracellular signal: environmental regulation of Salmonella virulence. Cell 84, 165-174. doi: 10.1016/S0092-8674(00)81003-X

Gotoh, Y., Doi, A., Furuta, E., Dubrac, S., Ishizaki, Y., Okada, M., et al. (2010). Novel antibacterial compounds specifically targeting the essential WalR response regulator. J. Antibiot. 63, 127-134. doi: 10.1038/ja. 2010.4

Groisman, E. A. (2001). The pleiotropic two-component regulatory system PhoPPhoQ. J. Bacteriol. 183, 1835-1842. doi: 10.1128/JB.183.6.1835-1842.2001

Guina, T., Yi, E. C., Wang, H., Hackett, M., and Miller, S. I. (2000). A PhoP-regulated outer membrane protease of Salmonella enterica serovar typhimurium promotes resistance to alpha-helical antimicrobial peptides. J. Bacteriol. 182, 4077-4086. doi: 10.1128/JB.182.14.4077-408 6.2000

Gunn, J. S., and Miller, S. I. (1996). PhoP-PhoQ activates transcription of pmrAB, encoding a two-component regulatory system involved in Salmonella typhimurium antimicrobial peptide resistance. J. Bacteriol. 178, 6857-6864. doi: 10.1128/JB.178.23.6857-6864.1996

Han, S., Bishop, B. M., and van Hoek, M. L. (2008). Antimicrobial activity of human beta-defensins and induction by Francisella. Biochem. Biophys. Res. Commun. 371, 670-674. doi: 10.1016/j.bbrc.2008.04.092

Howden, B. P., McEvoy, C. R., Allen, D. L., Chua, K., Gao, W., Harrison, P. F., et al. (2011). Evolution of multidrug resistance during Staphylococcus aureus infection involves mutation of the essential two component regulator WalKR. PLoS Pathog. 7:e1002359. doi: 10.1371/journal.ppat.1002359

Ito, A., Taniuchi, A., May, T., Kawata, K., and Okabe, S. (2009). Increased antibiotic resistance of Escherichia coli in mature biofilms. Appl. Environ. Microbiol. 75 , 4093-4100. doi: 10.1128/AEM.02949-08

Jones, C. L., Napier, B. A., Sampson, T. R., Llewellyn, A. C., Schroeder, M. R., and Weiss, D. S. (2012). Subversion of host recognition and defense systems by Francisella spp. Microbiol. Mol. Biol. Rev. 76, 383-404. doi: 10.1128/MMBR.05027-11

Kaushal, A., Gupta, K., Shah, R., and van Hoek, M. L. (2016). Antimicrobial activity of mosquito cecropin peptides against Francisella. Dev. Comp. Immunol. 63, 171-180. doi: 10.1016/j.dci.2016.05.018

Kingry, L. C., and Petersen, J. M. (2014). Comparative review of Francisella tularensis and Francisella novicida. Front. Cell. Infect. Microbiol. 4:35. doi: 10.3389/fcimb.2014.00035

Lai, X. H., Golovliov, I., and Sjostedt, A. (2004). Expression of IglC is necessary for intracellular growth and induction of apoptosis in murine macrophages by Francisella tularensis. Microb. Pathog. 37, 225-230. doi: 10.1016/j.micpath.2004.07.002

Larsson, P., Elfsmark, D., Svensson, K., Wikstrom, P., Forsman, M., Brettin, T., et al. (2009). Molecular evolutionary consequences of niche restriction in Francisella tularensis, a facultative intracellular pathogen. PLoS Pathog. 5:e1000472. doi: 10.1371/journal.ppat.1000472

Larsson, P., Oyston, P. C., Chain, P., Chu, M. C., Duffield, M., Fuxelius, H. H., et al. (2005). The complete genome sequence of Francisella tularensis, the causative agent of tularemia. Nat. Genet. 37, 153-159. doi: 10.1038/ng1499

Lejona, S., Aguirre, A., Cabeza, M. L., Garcia Vescovi, E., and Soncini, F. C. (2003). Molecular characterization of the Mg2+-responsive PhoPPhoQ regulon in Salmonella enterica. J. Bacteriol. 185, 6287-6294. doi: 10.1128/JB.185.21.6287-6294.2003

Li, Y., Powell, D. A., Shaffer, S. A., Rasko, D. A., Pelletier, M. R., Leszyk, J. D., et al. (2012). LPS remodeling is an evolved survival strategy for bacteria. Proc. Natl. Acad. Sci. U.S.A. 109, 8716-8721. doi: 10.1073/pnas.1202908109

Lindgren, H., Golovliov, I., Baranov, V., Ernst, R. K., Telepnev, M., and Sjostedt, A. (2004). Factors affecting the escape of Francisella tularensis from the phagolysosome. J. Med. Microbiol. 53, 953-958. doi: 10.1099/jmm.0.45685-0

Liu, B., Qin, Y., Wang, J., and Wang, Y. (2011). Detection and comparison of protein-DNA interactions using DNA-BIND plate and horseradish peroxidase-based colorimetric assay. Anal. Biochem. 412, 111-113. doi: 10.1016/j.ab.2011.01.008

Lou, Y. C., Weng, T. H., Li, Y. C., Kao, Y. F., Lin, W. F., Peng, H. L., et al. (2015). Structure and dynamics of polymyxin-resistance-associated response regulator PmrA in complex with promoter DNA. Nat. Commun. 6:8838. doi: $10.1038 /$ ncomms 9838

Maier, T. M., Havig, A., Casey, M., Nano, F. E., Frank, D. W., and Zahrt, T. C. (2004). Construction and characterization of a highly efficient Francisella shuttle plasmid. Appl. Environ. Microbiol. Microbiol. 70, 7511-7519. doi: 10.1128/AEM.70.12.7511-7519.2004

Margolis, J. J., El-Etr, S., Joubert, L. M., Moore, E., Robison, R., Rasley, A., et al. (2010). Contributions of Francisella tularensis subsp. novicida chitinases and sec secretion system to biofilm formation on chitin. Appl. Environ. Microbiol. 76, 596-608. doi: 10.1128/AEM.02037-09

McCoy, A. J., Grosse-Kunstleve, R. W., Adams, P. D., Winn, M. D., Storoni, L. C., and Read, R. J. (2007). Phaser crystallographic software. J. Appl. Crystallogr. 40, 658-674. doi: 10.1107/S0021889807021206

McKenney, E. S., Sargent, M., Khan, H., Uh, E., Jackson, E. R., San Jose, G., et al. (2012). Lipophilic prodrugs of FR900098 are antimicrobial against Francisella novicida in vivo and in vitro and show GlpT independent efficacy. PLOS ONE 7:e38167. doi: 10.1371/journal.pone.0038167

McMeechan, A., Lovell, M. A., Cogan, T. A., Marston, K. L., Humphrey, T. J., and Barrow, P. A. (2005). Glycogen production by different Salmonella enterica serotypes: contribution of functional glgC to virulence, intestinal colonization and environmental survival. Microbiology 151, 3969-3977. doi: 10.1099/mic.0.28292-0

McPhee, J. B., Bains, M., Winsor, G., Lewenza, S., Kwasnicka, A., Brazas, M. D., et al. (2006). Contribution of the PhoP-PhoQ and PmrA-PmrB two-component regulatory systems to $\mathrm{Mg} 2+$-induced gene regulation in Pseudomonas aeruginosa. J. Bacteriol. 188, 3995-4006. doi: 10.1128/JB.00053-06 
Menon, S., and Wang, S. (2011). Structure of the response regulator PhoP from Mycobacterium tuberculosis reveals a dimer through the receiver domain. Biochemistry 50, 5948-5957. doi: 10.1021/bi2005575

Milton, M. E., Allen, C. L., Feldmann, E. A., Bobay, B. G., Jung, D. K., Stephens, M. D., et al. (2017). Structure of the Francisella response regulator QseB receiver domain, and characterization of QseB inhibition by antibiofilm 2-aminoimidazole-based compounds. Mol. Microbiol. 106, 223-235. doi: 10.1111/mmi.13759

Minagawa, S., Ogasawara, H., Kato, A., Yamamoto, K., Eguchi, Y., Oshima, T., et al. (2003). Identification and molecular characterization of the Mg2+ stimulon of Escherichia coli. J. Bacteriol. 185, 3696-3702. doi: 10.1128/JB.185.13.3696-3702.2003

Mohapatra, N. P., Soni, S., Bell, B. L., Warren, R., Ernst, R. K., Muszynski, A., et al. (2007). Identification of an orphan response regulator required for the virulence of Francisella spp. and transcription of pathogenicity island genes. Infect. Immun. 75, 3305-3314. doi: 10.1128/IAI.00351-07

Montero, M., Almagro, G., Eydallin, G., Viale, A. M., Munoz, F. J., Bahaji, A., et al. (2011). Escherichia coli glycogen genes are organized in a single glgBXCAP transcriptional unit possessing an alternative suboperonic promoter within glgC that directs glgAP expression. Biochem. J. 433, 107-117. doi: 10.1042/BJ20101186

Morris, G. M., Huey, R., Lindstrom, W., Sanner, M. F., Belew, R. K., Goodsell, D. S., et al. (2009). AutoDock4 and AutoDockTools4: Automated docking with selective receptor flexibility. J. Comput. Chem. 30, 2785-2791. doi: $10.1002 /$ jcc. 21256

Moule, M. G., Monack, D. M., and Schneider, D. S. (2010). Reciprocal analysis of Francisella novicida infections of a drosophila melanogaster model reveal host-pathogen conflicts mediated by reactive oxygen and imd-regulated innate immune response. PLoS Pathog. 6:e1001065. doi: 10.1371/journal.ppat.1001065

Nano, F. E., Zhang, N., Cowley, S. C., Klose, K. E., Cheung, K. K., Roberts, M. J., et al. (2004). A Francisella tularensis pathogenicity island required for intramacrophage growth. J. Bacteriol. 186, 6430-6436. doi: 10.1128/JB.186.19.6430-6436.2004

Narayanan, A., Kumar, S., Evrard, A. N., Paul, L. N., and Yernool, D. A. (2014). An asymmetric heterodomain interface stabilizes a response regulator-DNA complex. Nat. Commun. 5:3282. doi: 10.1038/ncomms 4282

Niesen, F. H., Berglund, H., and Vedadi, M. (2007). The use of differential scanning fluorimetry to detect ligand interactions that promote protein stability. Nat. Protoc. 2, 2212-2221. doi: 10.1038/nprot.2007.321

Nishino, K., and Yamaguchi, A. (2001). Overexpression of the response regulator evgA of the two-component signal transduction system modulates multidrug resistance conferred by multidrug resistance transporters. J. Bacteriol. 183, 1455-1458. doi: 10.1128/JB.183.4.1455-1458.2001

O’Toole, G. A. (2011). Microtiter dish biofilm formation assay. J. Vis. Exp. 30:2437. doi: $10.3791 / 2437$

Otwinowski, Z., and Minor, W. (1997). Processing of X-ray diffraction data collected in oscillation mode. Methods Enzymol. 276, 307-326. doi: 10.1016/S0076-6879(97)76066-X

Oyston, P. C., Sjostedt, A., and Titball, R. W. (2004). Tularaemia: bioterrorism defence renews interest in Francisella tularensis. Nat. Rev. Microbiol. 2, 967-978. doi: 10.1038/nrmicro1045

Petersen, J. M., Carlson, J., Yockey, B., Pillai, S., Kuske, C., Garbalena, G., et al. (2009). Direct isolation of Francisella spp. from environmental samples. Lett. Appl. Microbiol. 48, 663-667. doi: 10.1111/j.1472-765X.2009.02589.x

Pierson, T., Matrakas, D., Taylor, Y. U., Manyam, G., Morozov, V. N., Zhou, W., et al. (2011). Proteomic characterization and functional analysis of outer membrane vesicles of Francisella novicida suggests possible role in virulence and use as a vaccine. J. Proteome Res. 10, 954-967. doi: 10.1021/pr1009756

Ramsey, K. M., and Dove, S. L. (2016). A response regulator promotes Francisella tularensis intramacrophage growth by repressing an anti-virulence factor. Mol. Microbiol. 101, 688-700. doi: 10.1111/mmi.13418

Rasko, D. A., Moreira, C. G., Li de, R., Reading, N. C., Ritchie, J. M., Waldor, M. K., et al. (2008). Targeting QseC signaling and virulence for antibiotic development. Science 321, 1078-1080. doi: 10.1126/science.1160354

Richards, M. I., Michell, S. L., and Oyston, P. C. (2008). An intracellularly inducible gene involved in virulence and polyphosphate production in Francisella. J. Med. Microbiol. 57, 1183-1192. doi: 10.1099/jmm.0.2008/001826-0
Robinson, M. D., McCarthy, D. J., and Smyth, G. K. (2010). edgeR: a Bioconductor package for differential expression analysis of digital gene expression data. Bioinformatics 26, 139-140. doi: 10.1093/bioinformatics/btp616

Sammons-Jackson, W. L., McClelland, K., Manch-Citron, J. N., Metzger, D. W., Bakshi, C. S., Garcia, E., et al. (2008). Generation and characterization of an attenuated mutant in a response regulator gene of Francisella tularensis live vaccine strain (LVS). DNA Cell. Biol. 27, 387-403. doi: 10.1089/dna.2007.0687

Schrodinger, L. (2010). The PyMOL Molecular Graphics System, Version 1.3r1.

Song, F., Guan, Z., and Raetz, C. R. (2009). Biosynthesis of undecaprenyl phosphate-galactosamine and undecaprenyl phosphate-glucose in Francisella novicida. Biochemistry 48, 1173-1182. doi: 10.1021/bi802212t

Stock, A. M., Robinson, V. L., and Goudreau, P. N. (2000). Twocomponent signal transduction. Annu. Rev. Biochem. 69, 183-215. doi: 10.1146/annurev.biochem.69.1.183

Su, J., Yang, J., Zhao, D., Kawula, T. H., Banas, J. A., and Zhang, J. R. (2007). Genome-wide identification of Francisella tularensis virulence determinants. Infect. Immun. 75, 3089-3101. doi: 10.1128/IAI.01865-06

Tanaka, K., Ishii, Y., Ogawa, J., and Shima, J. (2012). Enhancement of acetic acid tolerance in Saccharomyces cerevisiae by overexpression of the HAAl gene, encoding a transcriptional activator. Appl. Environ. Microbiol. 78, 8161-8163. doi: 10.1128/AEM.02356-12

Thompson, R. J., Bobay, B. G., Stowe, S. D., Olson, A. L., Peng, L., Su, Z., et al. (2012). Identification of BfmR, a response regulator involved in biofilm development, as a target for a 2-Aminoimidazole-based antibiofilm agent. Biochemistry 51, 9776-9778. doi: 10.1021/bi3015289

van Dijk, M., and Bonvin, A. M. (2009). 3D-DART: a DNA structure modelling server. Nucleic Acids Res. 37, W235-W239. doi: 10.1093/nar/gkp287

van Hoek, M. L. (2013). Biofilms: an advancement in our understanding of Francisella species. Virulence 4, 833-846. doi: 10.4161/viru.27023

van Hoek, M. L., Hoang, K. V., and Gunn, J. S. (2019). Two-component systems in francisella species. Front. Cell. Infect. Microbiol. 9:198. doi: $10.3389 /$ fcimb. 2019.00198

van Zundert, G. C. P., Rodrigues, J., Trellet, M., Schmitz, C., Kastritis, P. L., Karaca, E., et al. (2016). The HADDOCK2.2 web server: user-friendly integrative modeling of biomolecular complexes. J. Mol. Biol. 428, 720-725. doi: 10.1016/j.jmb.2015.09.014

Verhoeven, A. B., Durham-Colleran, M. W., Pierson, T., Boswell, W. T., and Van Hoek, M. L. (2010). Francisella philomiragia biofilm formation and interaction with the aquatic protist Acanthamoeba castellanii. Biol. Bull. 219, 178-188. doi: 10.1086/BBLv219n2p178

Wang, X., Ribeiro, A. A., Guan, Z., and Raetz, C. R. (2009). Identification of undecaprenyl phosphate-beta-D-galactosamine in Francisella novicida and its function in lipid A modification. Biochemistry 48, 1162-1172. doi: $10.1021 / \mathrm{bi} 802211 \mathrm{k}$

Wassenaar, T. A., van Dijk, M., Loureiro-Ferreira, N., van der Schot, G., de Vries, S. J., Schmitz, C., et al. (2012). WeNMR: structural biology on the grid. J. Grid Comput. 10, 743-767. doi: 10.1007/s10723-012-9246-Z

Zhang, Y., Mayba, O., Pfeiffer, A., Shi, H., Tepperman, J. M., Speed, T. P., et al. (2013). A quartet of PIF bHLH factors provides a transcriptionally centered signaling hub that regulates seedling morphogenesis through differential expression-patterning of shared target genes in arabidopsis. PLoS Genet. 9:e1003244. doi: 10.1371/journal.pgen.1003244

Zhou, D., Han, Y., Qin, L., Chen, Z., Qiu, J., Song, Y., et al. (2005). Transcriptome analysis of the $\mathrm{Mg} 2+$-responsive $\mathrm{PhoP}$ regulator in yersinia pestis. FEMS Microbiol. Lett. 250, 85-95. doi: 10.1016/j.femsle.2005.06.053

Conflict of Interest: The authors declare that the research was conducted in the absence of any commercial or financial relationships that could be construed as a potential conflict of interest.

Copyright (c) 2020 Dean, Milton, Cavanagh and van Hoek. This is an open-access article distributed under the terms of the Creative Commons Attribution License (CC $B Y)$. The use, distribution or reproduction in other forums is permitted, provided the original author(s) and the copyright owner(s) are credited and that the original publication in this journal is cited, in accordance with accepted academic practice. No use, distribution or reproduction is permitted which does not comply with these terms. 